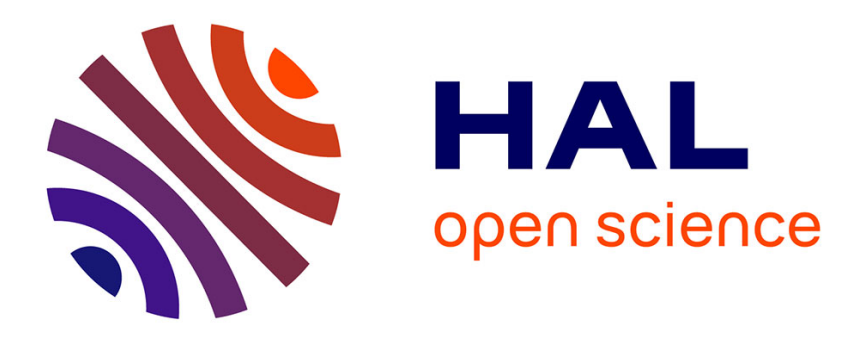

\title{
Price flexibility in channels of distribution: Evidence from scanner data
}

Shantanu Dutta, Mark Bergen, Daniel Levy

\section{To cite this version:}

Shantanu Dutta, Mark Bergen, Daniel Levy. Price flexibility in channels of distribution: Evidence from scanner data. Journal of Economic Dynamics and Control, 2002, 26 (11), pp.1845-1900. 10.1016/S0165-1889(01)00012-4 . hal-02386423

\section{HAL Id: hal-02386423 \\ https://hal.science/hal-02386423}

Submitted on 29 Nov 2019

HAL is a multi-disciplinary open access archive for the deposit and dissemination of scientific research documents, whether they are published or not. The documents may come from teaching and research institutions in France or abroad, or from public or private research centers.
L'archive ouverte pluridisciplinaire HAL, est destinée au dépôt et à la diffusion de documents scientifiques de niveau recherche, publiés ou non, émanant des établissements d'enseignement et de recherche français ou étrangers, des laboratoires publics ou privés. 


\title{
Price Flexibility in Channels of Distribution: Evidence from Scanner Data
}

\author{
Shantanu Dutta \\ Department of Marketing, Marshall School of Business, University of Southern California, \\ Los Angeles, CA 90089-1421, USA \\ Mark Bergen \\ Department of Logistics and Marketing Management, University of Minnesota, \\ Minneapolis, MN 55455, USA \\ Daniel Levy* \\ Department of Economics, Bar-Ilan University, Ramat-Gan 52900, Israel \\ Department of Economics, Emory University, Atlanta GA 30322-2240, USA
}

Last Revision: November 28, 2000

JEL Codes: E12, E31, L16

Key Words: Price Flexibility/Rigidity, Intermediate and Final Goods Markets, Stages of Processing

Acknowledgements:

We are grateful to the anonymous referee for thorough and insightful comments. We also thank the participants of the special Scanner Conference in Toronto, the Marketing Science conference in Tucson, the Southern Economic Association meeting, the American Economic Association meeting, the Marketing and the Economics and Legal Organizations Workshops at the University of Chicago, and Economics Workshops at the Federal Reserve Bank of Atlanta, Bar-Ilan, Emory, Georgia State, and York Universities, and the Georgia Institute of Technology for useful comments and suggestions. In addition, we thank the following individuals: Joshua Aizenman, Peter Aranson, Martin J. Bailey, Samiran Banerjee, George Benston, Dennis Carlton, Robert Carpenter, Pradeep Chintagunta, Robert Chirinko, Leif Danziger, Hashem Dezhbakhsh, Jo Anna Gray, Steve Hoch, Abel Jeuland, Eric Leeper, Andrew Levin (the discussant at the American Economic Association meetings), Georg Müller, Leonard Parsons, Peter Pashigian, Sam Peltzman, Joel Shrag, Carol Simon, Ruey Tsay, and Charles Weise (the discussant at the Southern Economic Association meetings) for their comments and suggestions. We would like to thank also numerous individuals from the Florida Department of Citrus, University of Florida Center for Citrus Research and Education, the Florida Agricultural Statistics Service, and Produce Manufacturing Association for patiently answering many of our questions and providing some of the data reported in this study. In particular, we would like to mention John Attaway, Sandy Barros, Carolyn Brown, Steve Irvin, Ed Moor, Ron Muraro, Bill Stinson, and Lola VanGilst. Helmut Lütkepohl kindly provided a Gauss program for doing the estimations performed in this paper. Particular thanks to Tao Zha for comments and for answering our questions. We gratefully acknowledge the research assistance of Ileana Aguilar, Joe Nunes, Yihong Xia, and Kang Kang Xu. Finally, we thank the University of Chicago for financial support and for providing access to their database. The third author acknowledges financial support also from Bar-Ilan University and the Science Division of the Israeli Ministry of Klita. All authors contributed equally to the paper: we rotate the order of coauthorship. The usual disclaimer applies.

* Correspondence: Daniel Levy, Department of Economics, Bar-Ilan University, Ramat-Gan 52900, Israel. Tel.: + 972-3-531-8345; Fax: + 972-3-535-3180. Email: Levyda@mail.biu.ac.il. 


\title{
Price Flexibility in Channels of Distribution: Evidence from Scanner Data
}

\begin{abstract}
In this study, we empirically examine the extent of price rigidity using a unique store-level time series data set-consisting of (i) actual retail transaction prices, (ii) actual wholesale transaction prices which represent both the retailers' costs and the prices received by manufacturers, and (iii) a measure of manufacturers' costs-for twelve goods in two widely used consumer product categories. We simultaneously examine the extent of price rigidity for each of the twelve products at both, final goods and intermediate goods levels. We study two notions of price rigidity employed in the existing literature: (i) the frequency of price changes, and (ii) the response of prices to exogenous cost changes. We find that retail prices exhibit remarkable flexibility in terms of both notions of price rigidity. i.e., they change frequently and they seem to respond quickly and fully to cost changes. Furthermore, we find that retail prices respond not just to their direct costs, but also to the upstream manufacturers' costs, which further reinforces the extent of the retail price flexibility. At the intermediate goods level of the market, in contrast, we find relatively more evidence of rigidity in the response of manufacturers prices to cost changes. This despite the fact that wholesale prices change frequently and therefore exhibit flexibility according to the first notion of price rigidity.
\end{abstract}


"Whether or not price rigidity is efficient, one common conclusion emerging from models with price rigidity is that markets with rigid prices behave very differently than markets with flexible prices. Therefore, an important unanswered question is, just how rigid are prices? Despite the great interest in this question, there have been virtually no attempts to answer it with data on individual transaction prices."

Dennis Carlton (1986, p. 637)

\section{Introduction}

Price rigidity, the apparent sluggish and incomplete response of prices to nominal shocks, is important enough to occupy a central stage in the research program of new Keynesian macroeconomics (e.g., Rotemberg, 1987; Mankiw and Romer, 1991; Ball and Mankiw, 1995; Blinder, 1982, 1994) and industrial organization (e.g., Stigler and Kindahl, 1970; Stiglitz, 1984; Bresnahan, 1989; and Carlton, 1989). Despite its central importance, the empirical evidence on the rigidity of prices is limited. As emphasized by authors such as Cecchetti (1986), Gordon (1990), and Kashyap (1995), there are only a handful of time series studies of price flexibility that use actual transaction prices. In this study, we empirically examine the extent of price rigidity using a unique store level time series data set—consisting of (i) actual retail transaction prices, (ii) actual wholesale transaction prices which represent both the retailers' marginal cost, and the prices received by manufacturers, and (iii) a measure of manufacturers' costs-for twelve goods in two widely used consumer product categories: six refrigerated orange juice products and six frozen concentrated orange juice products. The data set has several distinguishing features which make it particularly suitable for studying price rigidity. In particular, the cost data are exogenous with respect to prices and exhibit significant variation over the sample period. In addition, the products we study have constant quality.

We contribute to the literature on price rigidity in a number of ways. First, we examine two notions of price rigidity employed in the existing literature. We first examine price rigidity indirectly by studying the frequency of price changes, the distribution of the time interval between price changes, etc. However, as Blinder (1991, pp. 93-94) suggests, "From the point of view of macroeconomic theory, frequency of price changes may not be the right question to ask ... We are more interested to know how long price adjustments lag behind shocks to demand and cost." In fact, according to Carlton and Perloff's (1994) definition, "Price rigidity is said to occur when prices do not vary in response to fluctuations in costs and demand" (p. 722). The availability of cost data enables us to examine this, more direct, notion of price rigidity.

Second, our data allow us to assess the degree of retail price rigidity. Carlton (1986), Lach and Tsiddon (1992, 1996) and Warner and Barsky (1995), among others, suggest that store-level individual transaction price data are most appropriate for studying nominal price rigidity, since the retailer actually sets final goods prices. As the opening quotation from Carlton (1986) indicates, and as pointed out more recently also by Caplin (1993), Weiss (1993), and Wynne (1995) among others, unfortunately, only a handful of studies use actual transaction prices to study price rigidity. ${ }^{1}$ Further, our product categories are made up of 
small representative staple retail items which are often suggested as the most appropriate for studying price rigidity (Hannan and Berger, 1991; Neumark and Sharpe, 1993; and Ball and Mankiw, 1995).

Third, our data set allows us to study the extent of price rigidity at both retail (final good) and manufacturing (intermediate good) levels of the channel for the same twelve products we study, simultaneously. Most of the existing studies of price rigidity only study one level at a time, either the rigidity of intermediate goods prices or the rigidity of final goods prices. However, Gordon (1990) suggests the importance of simultaneously considering multiple levels of a market for studying price rigidity because of the interdependence of price and cost setting decisions across channels. We study the interaction between the manufacturing and retail levels by analyzing how upstream manufacturer cost changes (in addition to the direct costs) affect retail pricing decisions. The cross-channel comparison we make here is unique since the products compared across the two channels are identical.

And fourth, we use these data to empirically explore the relationship between stages of processing and price rigidity. Several authors such as Blanchard (1983), Mankiw (1985), Gordon (1990), and Basu (1995), suggest that the existence of stages of processing may be contributing to sluggish adjustment of final prices to upstream cost changes in many markets. For example, Blanchard (1983) shows that price rigidity will positively depend on the number of stages of processing. In this context, Gordon (1990) argues that prices will be more flexible in the case of "simple" products, that is, products produced using a small number of inputs.

To briefly summarize our descriptive statistical findings, we show that spot prices change almost every week and the size of the changes is highly variable. The wholesale price changes are heterogeneous in at least three respects: (i) refrigerated orange juice prices change more often than frozen concentrated orange juice prices; (ii) for both products there is a noticeable variation in the size of price changes as well as in the frequency of price changes; and (iii) even after controlling for the manufacturer, there are some consistent patterns in the size and frequency of price changes. For example, for refrigerated orange juice, the private label brand has more frequent price changes, but this is not true for frozen concentrated orange juice. Similarly, the brands that change prices most often, do not have the smallest average price change. Finally, the retail prices show most of the same characteristics as the wholesale prices. In particular, there is at best a loose correlation between the size of the average price changes and the frequency of the average price changes, and there are no consistent patterns as to which orange juice brands change prices most frequently or by the largest (or the smallest) amount. It does appear that frozen orange juice prices are less prone to

\footnotetext{
${ }^{1}$ For example, Weiss (1993, p. 15) emphasizes the importance of studying price rigidity using all “.... relevant information at the level of the firm, including costs and demand data." Similarly, Lach and Tsiddon (1992, p. 351) suggest to use actual transaction prices to study price rigidity because they "... most closely resemble the data envisioned by the cost of adjustment theory: price quotations at the level of the price setter."
} 
change and usually change by smaller percentage amounts. One difference, however, we find between the retail and wholesale prices is that unlike the latter, the former is subject to frequent promotional sales.

In terms of price rigidity, at the retail level we find that retail transaction prices are flexible in terms of both notions of price rigidity: (i) they change frequently, and (ii) they respond quickly and fully to changes in costs. This finding suggests that retail prices of some consumer goods may be more flexible than documented in the existing literature. At the intermediate level we find evidence of the second notion of price rigidity, i.e., rigidity in the response of manufacturers prices to their cost changes. We find this rigidity even though wholesale prices change frequently and therefore exhibit flexibility according to the first notion.

But perhaps the most striking finding we report in this paper is that the retail prices seem to respond not just to their direct costs, but also to the upstream manufacturers' costs. This reinforces the finding of retail price flexibility, and suggests that it is important to view prices in the context of all costs, both direct and indirect. In the market we study, therefore, the existence of stages of processing does not seem to be a barrier to the downstream passthrough of cost shocks. This is because in this market, the production channel consists of only two stages of processing. This allows cost change information quickly flow downstream which leads to a fast passthrough of cost changes onto prices. Also considering the orange juice market structure and given that the products we study are "simple" in the sense that the number of inputs used in their production is small, perhaps it should not be surprising that we find this retail price flexibility.

The paper is organized as follows. We begin with a section describing the data set used in this study. In section 3 we describe the econometric model, provide the definitions of price rigidity/flexibility we employ, discuss data transformation and sensitivity analysis, present the integration and cointegration tests' results, and provide details of the VAR specification and VAR residual correlation analysis. Next, in section 4, we discuss our results for the retail level of the channel followed by the discussion of the results for the wholesale level of the channel in section 5. We end with conclusions and future extensions.

\section{Data}

Our data set consists of 88 weekly observations from October 5, 1989 to June 6, 1991. It consists of spot prices of frozen concentrated orange juice, and the wholesale and retail prices of three brands of orange juice (two national brands, Tropicana and Minute Maid, and one private or in-house store label, Heritage House) in two product categories (frozen concentrated and refrigerated made from frozen concentrate). Each brand of frozen concentrated orange juice comes in two sizes, $12 \mathrm{oz}$ (which is considered the standard size) and 16oz. Similarly, each brand of refrigerated orange juice made from concentrate comes in two sizes, 64oz (which is considered the standard size) and 96oz (128oz for Heritage House). Thus, we study a total of 12 products. The spot prices are constructed from the futures price of frozen concentrated orange juice as reported by the New York Cotton Exchange (NYCE). The wholesale and retail prices come from a scanner 
data set of Dominick's, a large Midwestern supermarket chain operating over 80 stores throughout Midwest. The pricing, inventory management, purchasing, and promotion practices at Dominick's are representative of many large U.S. grocery chains.

To better understand the data we use, we present in Figure 1a a general schematic description of the organizational structure of the frozen concentrated orange juice market. Orange juice growers sell the fruit to orange juice processors who convert the oranges into frozen concentrate. There are two types of processors: one group of processors are privately owned and produce orange juice for private label. The other group of processors are owned by national orange juice manufacturers like Tropicana and Minute Maid, and they produce nationally branded products. These manufacturers package and sell the concentrated juice to retailers, either in its frozen form or reconstituted from concentrate and packaged as refrigerated juice.

In this paper we study two levels of the distribution channel: the retail level which represents the final goods level of the market, and the manufacturer level which represents the intermediate goods level of the market. $^{2}$ As Figure 1a suggests, the market we study has a hierarchical structure similar to the stages-ofprocessing structure of Blanchard (1983). This is different from the input-output view of the market organization which is more suitable for more aggregated and more complex products produced using many inputs (Meltzer, 1994; Basu, 1995, and Gordon, 1990). Here, by contrast, we study individual products, and also the products themselves are simple, produced with only few inputs.

The data set has several unique features which make it particularly suitable for studying price rigidity: (1) Actual retail transaction prices: For the final price to consumers at the retail level, we use weekly scanner data from a large Midwestern supermarket chain, Dominick's. These are the actual transaction prices consumers paid at the cash register each week. If the item was on sale, then the price data we have reflects the sale price. ${ }^{3}$ The retail prices are set on a chain-wide basis at the corporate headquarters of Dominick's and the data we have comes from a representative store of this chain. The advantage of using actual storelevel price data over aggregate price indices (such as those constructed by the Bureau of Labor Statistics) for studying price rigidity is that individual product price data collected at the store level most closely resemble the data envisioned by nominal price adjustment theories, since this is where prices are actually set. Further, by using the actual transaction price data, we avoid potential biases associated with the use of more aggregated data (Carlton, 1989). ${ }^{4}$

\footnotetext{
${ }^{2}$ In this paper the cost-price relationship at the manufacturing (intermediate goods) stage is described as spot-to-wholesale, and the cost-price relationship at the retail (final goods) stage is described as wholesale-to-retail. Similarly, in the case of the effect of upstream costs on retail price, we use the term spot-to-retail.

${ }^{3}$ Our retail prices reflect any retailer's coupons or discounts, but do not include manufacturer coupons. Fortunately, during the period covered in this study manufacturer coupons were rarely used to promote orange juice sale in this market. Further, these product categories are not used by Dominick's as loss-leaders.

${ }^{4}$ There is a rich literature in marketing that has used transaction level data to explore various issues including consumer choice behavior (Winer, 1986; Krishnamurthi and Raj, 1988; Steckel and Vanhonacker, 1988; Kamakura and Russell, 1989; and
} 
(2) Wholesale Prices: Actual retail cost and actual manufacturers' prices : As a measure of the direct cost to the retailer, we use the actual price the retailer paid the orange juice manufacturer, i.e., the wholesale price. The wholesale price was computed from the information provided by the retailer on their retail prices and weekly margins for each product. ${ }^{5}$ Having access to this cost data allows us to use a direct measure of cost rather than an indirect or aggregate measure such as GNP deflator, CPI, etc, and enables us to study the second notion of price rigidity: how prices respond to direct cost changes. Further, access to retail costs is rare. Even in studies that use scanner data, retailer costs are usually proprietary and seldom reported.

The wholesale price is the actual price the manufacturers receive from the retailer, and enables us to study patterns of price rigidity at the manufacturing stage of the channel. Again, this actual transaction price is particularly appropriate for studying price rigidity and eliminates possible biases associated with the use of more aggregate price indices. The availability of actual transaction prices for the same products at two levels of the distribution channel is another unique aspect of this data set.

(3) Manufacturers' costs: For the manufacturers of the products we study, the cost of orange juice concentrate input constitutes the bulk of the total cost (Ward and Kilmer, 1989). As a measure of this cost we use the spot market price for that week. To arrive at the spot cost, we use the nearest futures price of frozen concentrated orange juice in the commodities' exchange market. ${ }^{6}$ This nearest futures price is adjusted for storage and carrying costs to get the spot cost using the cash-and-carry arbitrage formula. ${ }^{7}$

Gonul and Srinivasan, 1993), brand choice (Carpenter and Lehmann, 1985; Krishnamurthi and Raj, 1988; Blattberg and Wisniewski, 1989; Lattin and Bucklin, 1989; Allenby and Rossi, 1991; Chintagunta et al., 1991; and Villas-Boas and Winer, 1999), purchase incidence (Schmittlein et al., 1993; and Gupta, 1988), store level elasticity (Hoch et al., 1995) and pricing strategy (Dhar and Hoch, 1997; and Raju et al., 1995).

${ }^{5}$ Wholesale price $=(1-$ margin $\%)$ multiplied by the retail price. The wholesale price is computed by the retailer as the weighted average of the amount the retailer paid for all their inventory. For example, if the retailer bought its current stock of frozen concentrate Tropicana $12 \mathrm{oz}$ in two transactions, the wholesale price is computed as the average of these two transaction prices. No FIFO or LIFO accounting rules are used in these computations. The effect of these calculations on the accuracy of the wholesale price series is not likely to be large since the inventory turnover in the orange juice category is very fast: frozen orange juice turns over every 6-7 days and refrigerated orange juice turns over every 7-9 days. (The reason for this high turn over rate is the high storage cost of both types of juice.) Since the inventory turns over approximately once a week, the wholesale price is quite reflective of the current manufacturer wholesale price. It should be noted also that this wholesale price does not include lumpy payments like slotting allowances. However, our discussion with the managers who set the retail prices indicate that these kind of payments were not common in the orange juice category during the period we cover. Further, these managers indicated that they rely on this wholesale price series for making their pricing decisions. The wholesale price series we use were computed using the retail price and margin information. The source of both series is the scanner database.

${ }^{6}$ The nearest futures price was collected from the Wall Street Journal on Thursday of each week which reports the price set at the Wednesday's trade. Wednesday's price data were chosen in order to match them with the price change decision day of the week, which is usually Thursday. These price change decisions are based on variety of information (costs, competitors prices, sales, etc.) the retailers routinely collect for price managers to use (Dutta, et al., 1999, Levy, et al., 1997, and 1998, Müller, et al., 1997). The market trades in futures contracts with contract maturity ranging from 2 to 18 months. Citrus Associates, which include the processors, manufacturers, institutional investors, and brokerage firms are the main players in this market.

${ }^{7}$ The storage cost is computed using the interest rate on 6-month treasury bill at that time and monthly carrying cost is based on the information provided by NYCE. Similar procedures are also used in the finance literature (e.g., French, 1986; Fama and French, 1987). The use of nearest futures price as a proxy of the spot price means that once each month there is a possible change from the month $n$ contract to the month $n+1$ contract which may pose a problem. The adjustment of these series for storage and carrying cost is designed to resolve this problem. 
For this we used information provided by the NYCE which uses this method routinely to compute and adjust current and futures prices. The computed spot cost was divided by 1600 to get a dollar/oz price of frozen orange concentrate. The price quoted at NYCE is for orange concentrate level of 57 degree brix. A brix is a measure of the pounds of solids and the sugar content in one gallon of juice. The brix level for frozen orange concentrate (both national brand and private label) is 41.8 and the brix level for refrigerated juice (both national brand and private label) is 11.7. So we adjusted downwards the NYCE spot price to ensure similar quality as measured by brix solid content per oz.

We use the spot price as a proxy for the price at which the manufacturers purchase the frozen concentrated orange juice. ${ }^{8}$ We believe that the use of this proxy is reasonable for the following reasons. Manufacturers can acquire frozen concentrated orange juice in two main ways. First, they can purchase it at current price, which reflects current market supply and demand conditions, from either (a) independent growers, (b) growers participation plans which sell the product together, or (c) cooperatives of orange growers. Second, they can sign a contract with growers. The contract may either (a) specify a price, (b) leave the price open to be determined at the time of delivery, or (c) include a minimum guaranteed price in return for longer term commitment. In addition, the contract may specify the minimum fruit quality, payment basis and scheme, and the quantity. The average share of frozen concentrated orange juice sold through these different arrangements during the 1980s is as follows: 4.5 percent from independent growers, 14.5 percent through participation plans, 47.5 percent from growers cooperatives, and 33.5 percent through contracts with growers (Ward and Kilmer, 1989, Table 3.3). Thus, at least 67 percent of the frozen concentrated orange juice sold is based on market prices which reflect current supply and demand conditions, and the prices of a large portion of the remaining 33 percent may also be based on market conditions since, as mentioned above, many contracts may leave the price open. Since the spot price reflects current and expected market supply, market demand, and weather conditions, and since, as mentioned above, 2/3 or more of the frozen concentrated orange juice is sold at prices that reflect current market conditions, the spot price and the manufacturers purchase price are correlated (Ward and Kilmer, 1989). In addition, the manufacturers are major traders in the NYCE and therefore, the prices set at this market should be related to the costs incurred by them. It should also be noted, that this cost proxy is still more micro-based than many aggregate cost measures that have been used to study price rigidity in the past (such as GNP deflators, CPI, etc.).

(4) Weekly time series: The frequency of the time series we use is weekly. This is particularly useful for studying price adjustment with Dominick's data since pricing at Dominick's is done on a weekly basis. i.e., the chain changes prices only once a week. ${ }^{9}$

\footnotetext{
${ }^{8}$ The use of spot price as a proxy for manufacturers' costs is also necessitated by the fact that the market prices at which the manufacturers purchase the frozen concentrated orange juice are not publicly available on a weekly basis.

${ }^{9}$ Levy, et al. (1997, Table VI) document the actual number of price changes and their frequency for large U.S. supermarket
} 
(5) Stages of processing: By collecting data on manufacturers' costs we are able to study retail reactions to wholesale and upstream cost changes simultaneously. Given the two-stage vertical distribution structure of the market we study, our data set enables us to examine the role of stages of processing in the retail price rigidity. Further, we are able to compare the rigidity of prices across the two channels. This comparison is particularly "clean" since the products compared across the two channels are identical, even the packaging is the same: "Generally this represents transformation in time and space only, since most citrus products are produced in their final consumable form at the packer or processor level" (Ward and Kilmer, 1989, p. 36). The only difference between the two channels of distribution is the sellers' and buyers' identity: at the manufacturing level, the sellers are manufacturers and the buyers are the retail stores, while at the retail level, the sellers are retail stores and the buyers are the general public.

(6) Exogenous cost changes: With these data, we examine the effect of exogenous cost changes on prices almost as if it were a controlled experiment. Changes in retail cost are exogenous with respect to retail price because: (i) the market we study is of a hierarchical nature since the retailer follows the manufacturers and manufacturers follow orange growers in the channel of vertical distribution; (ii) the manufacturers in this study sell nationally, while the retailer we study is one of many regional sellers in the Chicago metropolitan area; and (iii) as an orange juice seller, the retailer is significantly smaller than the national manufacturers. For similar reasons, we argue that the commodity spot cost can be treated as exogenous with respect to the wholesale as well as retail prices, as suggested by Roll (1984) and Baur and Orazem (1994). ${ }^{10}$

(7) Cost and price variation: For studying price rigidity, an ideal data set would provide prices of a product over a period of time long enough for there to have been significant change in market conditions. The orange juice price and cost data we use satisfy this requirement. We use weekly data, during which some extreme weather changes affected the orange juice market conditions significantly. Indeed, descriptive statistics reported in Tables 1-5 and the time series plotted in Figure $1 \mathrm{~b}$ indicate a significant variation in these prices and costs over our sample period.

(8) Constant quality: The quality of orange juice products is kept constant. The quality of orange solids is guaranteed by standardized concentration and minimum "scores" for color and flavor. The minimum standards for Florida juice are set by the Florida Department of Citrus and the US Department of Agriculture. ${ }^{11}$ The juice quality is determined based on sugar and acid content of the juice and the amount

chains. They find that in their sample of representative stores the price changes are usually done on a weekly basis according to the following schedule: prices of advertised general merchandise are changed every Saturday afternoon, prices of advertised grocery - every Tuesday afternoon, prices of general merchandise-every Monday afternoon, prices of grocery-every Sunday afternoon, etc. A similar price change schedule has been documented for large US chain drugstores (Dutta, et al., 1999).

${ }^{10}$ We find no evidence of changes in the market power of the downstream firms over the sample period.

${ }^{11}$ For example, a typical frozen concentrate orange juice futures contract may be specified as follows: "U.S. Grade A with a brix value of not less than $51^{\circ}$ having a brix value to acid ratio of not less than 13.0 to 1 nor more than 19.0 to 1 and a minimum score of 94, with the factor of color and flavor each scoring 37 points or higher, and defects at 19 or better..." (Roll, 
of orange solids in the crop. Frozen concentrated orange juice quality is further controlled by setting upper limits on the amount of sinking and washed pulp solids. Also, the concentrated orange juice needs to pass the gel test which guarantees that no gel pulp will be left after reconstitution. In the retail market, the minimum brix content of frozen concentrated and refrigerated orange juice (both national brand and private label) are $41.8^{\circ}$ and $11.7^{\circ}$, respectively. Any decrease in these figures would amount to cheating. ${ }^{12}$

(9) Widely consumed, representative, small staple retail item : As Ball and Mankiw (1994) indicate, for the purpose of explaining monetary non-neutrality, the most important prices are for those goods which are purchased with money such as small retail items, because the prices of goods bought with credit may not directly affect the demand for money. The groceries sold by this supermarket chain could not be purchased on credit during our sample period. Further, the products we study are purchased by consumers on a weekly basis and are a part of a regular family shopping basket. The annual sales of frozen concentrated orange juice is approximately \$1 billion on 170 million gallons of output (Wall Street Journal, July 12, 1990) which makes these economically significant product categories. Thus, it is a representative and widely consumed retail item. In addition, the pricing practices of the specific retail chain we study are representative of many large U.S. retail grocery chains. Further, supermarket chains account for 70 percent of retail food store sales in the U.S. (Progressive Grocer, 1989). ${ }^{13}$

(10) No quantity adjustment: A large-scale quantity adjustment in response to cost changes is unlikely in this market because of the high storage cost of the products studied here. ${ }^{14}$ At the manufacturing level, if a contract is signed between growers and processors, the quantity of the product to be delivered is usually specified in advance in either of the two forms: under "production contract" the buyer takes all of the production from a grove, while under a "limit contract" the exact quantity to be delivered is specified.

(11) Stable demand: The empirical findings reported by Roll (1984), Ward and Kilmer (1989), and studies cited therein indicate that most of the orange juice commodity price volatility at the manufacturing level is due to supply shocks. The studies conducted by Florida Citrus Commission and University of

1984, p. 867).

${ }^{12}$ While cheating is believed to be a rare phenomenon in this market, we were able to find one documented case. According to the New York Times (July 27, 1989, section D, p. 14, column 1), on July 25, 1989, a Federal Grand Jury indicted three former owners of Bodine's Inc., for allegedly selling under 50 different labels a phony frozen concentrated orange juice during the 1978-85 period. According to the indictment, the accused have developed a recipe using beet sugar, corn sugar, monosodium glutamate, and other "low cost, inferior ingredients" and sold the product as $100 \%$ frozen concentrated orange juice. The individuals were eventually convicted and sent to 2-year prison terms (Crain's Chicago Business, March 5, 1990, p. 8). Kroger was one of the supermarket chains later charged for knowingly selling Bodine's Inc.'s fake juice under its label, a charge which they denied (The New York Times, August 22, 1989, section D., p. 4, column 1).

${ }^{13}$ During 1988 there were 30,754 supermarkets in the U.S. and 55 percent of them belonged to chains of eleven or more stores (Chevalier, 1995).

${ }^{14}$ In terms of retail inventory management, typical chains usually store the juice (both frozen and concentrate) in metropolitan warehouses. The manufacturers deliver the products to these warehouses about twice a week. The amount of inventory held in these warehouses is on average about 2-3 days supply. Because of the high storage cost, retailers try hard to avoid larger inventory holdings. 
Florida Center for Citrus Research and Education (see, for example, Ward and Kilmer, 1989, and the references cited therein) reach a similar conclusion for the retail level. Cagan (1974, p. 22), in summarizing the existing econometric evidence, also argues that "Empirical studies have long found that short-run shifts in demand have small and often insignificant effect [on prices], and that, instead, costs play a dominant role." 15 In addition, we searched the relevant trade publications and major national and Midwestern newspapers, and found no evidence of demand changes during the sample period, which is not surprising: variation in orange juice demand is unlikely since orange juice is a staple item that is consumed on a weekly basis, similar to milk and bread. Therefore, we assume that most of the variation in the product prices we study is driven by supply shocks. Thus, we abstract from demand shocks and try to explain all the variation in prices using costs, as in Borenstein et al. (1992), and Borenstein and Shepard (1995). Another advantage of the absence of significant demand shocks is that it minimizes the possibility of an endogeneity bias.

\section{The Econometric Model and Cointegration Tests}

In this section we formulate the econometric model which is specified in the Structural VectorAutoregressive (VAR) framework (section 3.1). In section 3.2. we address the choices we made in defining price rigidity and price flexibility for interpreting the VAR results. Data transformation and sensitivity analysis is discussed in section 3.3, followed by presentation of the results of necessary time series tests which include the integration (section 3.4) and cointegration (section 3.5) tests. We discuss the results of the VAR specification and residual correlation tests in section 3.6.

\subsection{The Econometric Model}

Of the authors who have empirically examined the evidence on cost-price relationships in various markets, most have studied single channel relationships, or at least treated them as separate, and therefore estimate models incorporating various types of distributed lag structures, which are particularly suitable for studying single channel relationships. ${ }^{16}$ However, in this paper we are interested in evaluating the dynamic effect of changes in the manufacturer's commodity input cost and retailer's cost on the retail price, and in the dynamic effect of changes in the manufacturer's commodity input cost on manufacturer wholesale price, simultaneously. This spot-to-wholesale-to-retail market organization contains not one, but two channels. Since one cannot exclude the possibility that the spot price may affect the wholesale and retail prices simultaneously, it is preferable to model the dynamic relationship in the two channels simultaneously. Therefore, we use Structural Vector Autoregression (VAR) modelling technique. ${ }^{17}$

\footnotetext{
15 Okun (1981, p. 176) also states that “... retail trade displays no significant markup responsiveness to shifts in demand."

${ }^{16}$ An issue related to price rigidity that is not addressed in this paper is asymmetry in the response of prices to cost changes. We choose not to address this here because preliminary analysis of the data does not indicate a presence of asymmetry.

${ }^{17}$ In fact, in early work with the data we also studied the relationship between spot costs and wholesale prices separately and the relationship between wholesale prices and final retail prices separately. However, a visual inspection of the time series of
} 
In this paper we estimate a restricted three-dimensional VAR model. The three variables are the spot cost, the wholesale price, and the retail price. The VAR model we estimate is given by the matrix equation

$$
y_{t}=\alpha+\sum_{i=1}^{p} A_{i} y_{t-i}+\varepsilon_{t}
$$

where $y_{1}$ is a $(3 \times 1)$ vector of $\operatorname{spot}\left(y_{1}\right)$, wholesale $\left(y_{2}\right)$, and retail $\left(y_{3}\right)$ prices respectively, $\alpha$ is a $(3 \times 1)$ vector of constants, $p$ is the lag length, $\varepsilon_{t}$ is a $(3 \times 1)$ vector of white noise residuals, and $A_{i}$ is a $(3 \times 3)$ matrix of the VAR coefficients

$$
A_{i}=\left[\begin{array}{lll}
a_{11, i} & a_{12, i} & a_{13, i} \\
a_{21, i} & a_{22, i} & a_{23, i} \\
a_{31, i} & a_{32, i} & a_{33, i}
\end{array}\right] .
$$

The structural identification restrictions we impose on the VAR coefficients follow from our economic reasoning which in this particular case is primarily based on the hierarchical, vertical distribution channel structure of the market we are studying. Manufacturers (processors) follow orange growers in the commodities market and retailers follow manufacturers in the distribution channel of the orange juice market. In addition, the manufacturers of orange juice sell nationally, while the retailer we study is one of many regional sellers in the Chicago metropolitan area. Also, as an orange juice seller, the retailer is significantly smaller than the orange juice manufacturers themselves.

Given this vertical distribution channel structure of the orange juice market, we assume that a change in the spot price may affect the wholesale price as well as the retail price. In addition, we expect the wholesale price to affect the retail price. However, we do not expect the retail price to affect the wholesale price or the spot price. Similarly, we do not expect the wholesale price to affect the spot price. Given the hierarchical structure of the spot-to-wholesale-to-retail channel of the orange juice market, and given the decrease in the size of the seller as we move down the channel from spot to wholesale to retail, we believe that these restrictions are sensible. ${ }^{18}$

In terms of the notation used in (1)-(2) above, these identifying restrictions mean that we set $a_{12, i}=0, a_{13, i}=0$, and $a_{23, i}=0$, which makes the $A_{i}$ matrix lower triangular:

spot, wholesale, and retail prices of orange juice (see, for example, Figure 1b, which is representative) reveals that very often, when spot price starts to increase, the retail price also starts to increase, almost immediately. In fact, sometimes it looks like the retail price reacts to the spot cost changes even faster than the wholesale price. Thus we use a methodology that allows us to simultaneously estimate the effects of the spot cost shocks on the wholesale and final retail prices.

${ }^{18}$ These exogeneity assumptions are similar to the assumptions frequently employed in the empirical industrial organization and in the empirical macroeconomic literature when researchers rule out the possibility of some disaggregated variable, for example, individual firm's balance sheet, to affect more aggregate behavior, for example, industry sales (Pagan, 1995; Gilchrist and Zakrajsek, 1995; and Zha, 1999). The findings reported by Roll (1984) and Baur and Orazem (1994) also support these exogeneity assumptions. 


$$
A_{i}=\left[\begin{array}{ccc}
a_{11, i} & 0 & 0 \\
a_{21, i} & a_{22, i} & 0 \\
a_{31, i} & a_{32, i} & a_{33, i}
\end{array}\right] .
$$

Thus, in the three equation VAR we estimate, in the first equation we have the spot price as the dependent variable and its own lags as the right hand side variables, in the second equation we have the wholesale price as the dependent variable and its own lags as well as lags of the spot price as the right hand side variables, and in the third equation we have the retail price as the dependent variable and its own lags as well as lags of the wholesale and spot prices as the right hand side variables. ${ }^{19}$ These identifying restrictions impose a block-recursive structure on the VAR coefficients, which makes the spot price $\left(y_{1}\right)$ exogenous with respect to the wholesale $\left(y_{2}\right)$ and the retail price $\left(y_{3}\right)$, and the wholesale price $\left(y_{2}\right)$ exogenous with respect to the retail price $\left(y_{3}\right)$. To separate the residuals of the estimated VAR into orthogonalized innovations for the purpose of structural identification of the model, we impose on them a set of restrictions identical to the restrictions imposed on the VAR coefficients. Following Lütkepohl's (1990) suggestion, we use the residuals of the restricted model to orthogonalize the innovations for the impulse response analysis.

To quantify the idea of dynamic price adjustment to cost changes, we present the cumulative impulse responses instead of the usual impulse responses. All three variables are price variables measured in dollars per brix solid oz. Therefore, to make the interpretation of the results more intuitive, we convert the vertical axis scale of the impulse responses into dollars by appropriately adjusting the estimated impulse response and the corresponding confidence interval figures. Thus, instead of the common practice of presenting the response of price to a one standard deviation shock in cost, we present the response of price in dollars to a one dollar shock in cost. We also present the variance decomposition of the series. Along with the estimated impulse response and variance decompositions we also report corresponding $90 \%$ confidence intervals. These were computed using the asymptotic distribution results reported by Lütkepohl (1990). ${ }^{20}$

\subsection{Interpretation of the VAR Results in Terms of Price Rigidity/Flexibility}

The notion of price rigidity is most relevant in the short run, since in the long run prices are flexible. Therefore, we define price rigidity as an incomplete response of prices to cost shocks in the short run. Recall that the traditional economic definition of long run is the time horizon it takes the particular market to completely adjust to all the information. To operationalize this definition, we communicated with various

\footnotetext{
${ }^{19}$ A VAR model with linear restrictions of the type employed here is often called a subset VAR (Lütkepohl, 1991). In the terminology of Zha (1999), the model we estimate here is strongly contemporaneous block recursive.

${ }^{20}$ It turns out that the small sample properties of these standard errors do not differ much from the properties of the standard errors estimated based on more commonly used Monte Carlo integration, bootstrap, or other resampling methods (Lütkepohl, 1990 and 1991). However, the computational simplicity and the speed of the asymptotic distribution method makes this approach significantly cheaper (Lütkepohl, 1990). See Sims and Zha (1999) and Zha (1999) for a Bayesian perspective on this.
} 
orange juice market participants, such as the retail buyer, some manufacturers, and Florida Citrus Commission officials. These conversations suggest that a twelve to sixteen week period or longer would be considered long run (i.e. the time horizon it takes this market to completely adjust to all the information) and that an eight-week period or shorter would be considered short run. Using this information as the guideline, we define the first eight-week period after the occurrence of the shock as the short run and twelve-week and longer horizon as the long run.

Although the use of cumulative impulse response functions makes the empirical analysis of price rigidity simple since it enables us to compare and rank the cumulative reactions of prices to cost shocks (e.g., the smaller the cumulative response, the more rigid the prices are), it is still necessary to adopt some ad hoc criteria for establishing the rigidity/flexibility of prices. Since picking any particular cut off point of the cumulative impulse response function is difficult to defend, we consider two possible extreme values of pass through, one corresponding to a complete price flexibility and the other corresponding to a complete price rigidity. If prices adjust completely to cost shocks in the short run (i.e., one-dollar increase in cost leads to a cumulative one-dollar increase in price), which is what we'd expect under perfect competition, then we say that prices are flexible. If prices do not adjust in the short run, then we say that prices are rigid.

Thus, two specific values of the cumulative impulse response function we consider below are zero and one. If the 8th week confidence interval of the cumulative impulse response function contains one but not zero (as, for example, in the case of refrigerated Tropicana, 96oz, wholesale-to-retail channel, Figure 2.1e), then the null of a full short-run price adjustment cannot be rejected. This would imply short-run price flexibility. If the confidence interval contains zero (or any figure between zero and one) but not one in the short run (as, for example, in the case of refrigerated Tropicana, 96oz, spot-to-wholesale channel, Figure 2.1d), then we interpret this as evidence of short-run price rigidity. We acknowledge, that the choice of these cut off points is not problem free. For example, the passthrough may be larger or smaller than one depending on competition, industry concentration, and market power. Also, using zero as a lower bound may be extreme in the sense that it may be unlikely to expect no passthrough after 8 weeks. The difficulty we face is that picking any other cutoff point seems at least as difficult to defend.

In the cases where the 8th week confidence interval of the cumulative impulse response function is too wide and contains both zero and one (as, for example, in the case of refrigerated Tropicana, 64oz, spotto-retail channel, Figure 2.1c), then we consider the central tendency of the true impulse response by looking at a more narrow confidence interval (for example, 1.00 standard error rather than 1.64 standard error). Since this is a weaker test of rigidity/flexibility, we denote flexible or rigid outcomes in these situation as either "tending toward flexibility" or "tending towards rigidity." For example, in the case of refrigerated Tropicana, 64oz, spot-to-retail channel, Figure 2.1c, the 8th week 1.64 standard deviation 
confidence interval contains both, zero and one, which makes it difficult to interpret. However, if we consider 1.00 standard deviation confidence interval, then zero does not fall in the 8th week confidence interval anymore, but one still remains. Therefore, we describe this case as "tending towards flexibility," which reflects the idea that it is only the central tendency we are describing given the width of confidence interval: it is more likely that the true value will tend towards one than zero. In Table 9 we have summarized these results for all 36 impulse response functions reported in this paper. For each channel, i.e., for each row, we have twelve impulse response functions which correspond to the twelve products we study.

\subsection{Data Transformation and Sensitivity Analysis}

As an example, the time series of spot cost, wholesale price, and retail price of frozen Heritage House, 12oz, are plotted on Figure 1b. The retail prices of ten of the twelve products we study exhibit a strong and recurring promotional sales activity, as indicated by the frequent price reductions in the plot of the retail price of Heritage House, 12oz, on Figure $1 b .^{21}$ These systematic promotional patterns are the standard practice for retailers of these and similar products.

When studying price rigidity by examining the effect of costs on prices, the question arises on how we should handle these systematic price reductions during sales promotions. On the one hand, these temporary price reductions might show up in the results, which we do not want since we would like to avoid mixing the issue of price rigidity as measured by the effect of cost changes on prices, with promotional sale activity of the retailer. On the other hand, we do not want to completely discard these promotional price changes because they represent the actual price to consumers. Therefore, to resolve this difficulty, we have decided to estimate the model outlined above using the original data as well as two sets of transformed data. This enables us to examine the sensitivity of the results we report in the paper to the presence of these sales.

The first transformation was done by applying a moving average to the wholesale and retail series. The choice of the width of the moving average window was dictated by the sales pattern. The data indicates that typically a product goes on sale approximately once during a four-to-six week period. Therefore, using a minimal window width of three would not always suffice to spread the sales effect onto non-sale periods. On the other hand, a window width that is too wide (such as seven, nine, or above) would spread the sales effect over too wide an interval. Thus we have used a window width of five. As an example, Figure 1c displays the moving averaged cost and price series for frozen concentrated Heritage House, $12 \mathrm{oz}^{22}$

\footnotetext{
21 The two exceptions are frozen Minute Maid and Heritage House, 16oz, which were never on sale during the sample period.

${ }^{22}$ We have also considered using monthly data by converting the weekly series into monthly which would essentially eliminate the price changes that occur due to the promotional sales activities. This could be done by sampling at monthly frequency either by (i) treating the first (or perhaps the fourth) weekly observation of each month as the monthly observation and dropping the other three weekly observations, etc., or by (ii) averaging over the four-week periods. The problem with either method is that this procedure would yield from the original 88 weekly observations only 22 monthly observations which would leave an insufficient degrees of freedom for estimating the structural VAR model we estimate. By using the method of moving averages, we are able to get rid of the sales at the cost of loosing only a minimal number of observations (degrees of freedom).
} 
The second transformation was done through smoothing of the series by eliminating the promotional sales from the data which enables us to use the list price instead of the sale price. Figure 1d displays as an example a plot of smoothed series along with the original series of frozen concentrated Heritage House, $12 \mathrm{oz}$. As the plot indicates, the two series coincide with the exception of the sales periods where the original series contain sale price spikes. ${ }^{23}$

\subsection{Integration Tests}

To determine the stationarity of the data, we formally examine unit root properties of all the time series of cost and price used in this study using the Augmented Dickey-Fuller (henceforth ADF) unit root test with a constant, a linear trend, and six lags. Initially, we test the hypothesis of an unit root in the series measured in levels. The results are reported in the first column of Table 6 . The values of the ADF $t$-statistics indicate that the null hypothesis of unit root nonstationarity cannot be rejected for any of the price or cost series. Next, we test whether the first differences of the series are nonstationary. As the figures presented in the second column of Table 6 indicate, the hypothesis of an unit root in the differenced series can be rejected at $1 \%$ significance in 18 of the 25 cases and at $5 \%$ or $10 \%$ for the remaining cases. Therefore, we conclude that all price and cost series are $I(1)$, and thus can be represented as difference stationary processes.

\subsection{Cointegration Tests}

For cointegration analysis we use Johansen's (1988) maximum likelihood approach. Although alternative approaches are available, studies have shown that Johansen's procedure has the best properties in the sense that it yields the least biased and the most symmetrically distributed coefficient estimates. This is true even when the errors are not normally distributed or when the underlying dynamics are unknown (Gonzalo, 1989). Johansen's method has the added advantage that it treats all variables as endogenous.

The cointegration test results are presented in Table 7 . The critical values we use are taken from Osterwald-Lenum (1992). We choose not to use the more commonly used critical values tabulated by Johansen and Juselius (1990) since Podivinsky (1990) suggests that those critical values may be invalid for sample sizes of 100 or smaller. In estimating the cointegration vectors, we set the order of the vector autoregression to 6 based on the test results of four lag selection criteria: Final Prediction Error (FPE), Akaike's Information Criterion (AIC), Hannan-Quinn Criterion (HQC), and Schwarz Criterion (SC). Since it is not known a priori whether the true data generating process contains a deterministic trend or not, we conduct the cointegration test under both possibilities. The test statistics are identical under both assumptions, only the critical values differ as the last four columns of Table 7 indicate.

In Johansen's framework the number of cointegrating vectors is determined sequentially. We start

\footnotetext{
${ }^{23}$ It should be noted that all the econometric work reported in this study was repeated for all three data sets (original, moving averaged, and smoothed) and since the main results are qualitatively similar, we only report the results for the moving averaged series. The remaining results are included in the referee's appendix which is available upon request.
} 
with the hypothesis that there are no cointegrating relations, that is, $r=0$, where $r$ denotes the number of cointegrating relationships. We continue only if this hypothesis is rejected. In that case we test the hypothesis that there is at most one cointegrating vector $(r \leq 1)$, and so on. The test results can be interpreted in favor of cointegration only if $0<r<m$, where $m$ denotes the number of variables in the data vector $\mathbf{y}_{t}$. Full rank, that is $r=m$, only indicates that the vector process $\mathbf{y}_{t}$ is stationary. If $r=0$, then the matrix $\Pi^{1}$, which is the matrix of coefficients on the variables $\mathbf{y}_{t-t}$ in the VAR model written in first differences, is the null matrix and then the model becomes a traditional differenced VAR model.

Johansen (1988) proposes two tests for estimating the number of cointegrating vectors and both are employed in this paper. The first, called maximal igenvalue test, is given by the statistic $\lambda_{\max }$, and is designed to test the hypothesis $H(r-1)$ against the hypothesis $H(r)$. The second test statistic $J_{T}$, called trace test, is designed for testing the hypothesis $H(r)$ against the hypothesis $H(m)$, where $r<m$. Following the sequential procedure outlined above, we applied the two cointegration tests to our data vector $\mathbf{y}_{t}$, which consists of three price-cost variables, the spot price, the wholesale price and the retail price. We run the test for all twelve products in a trivariate setting (spot, wholesale, and retail). The tests' results are reported in Table 7.

The results indicate that the null of no cointegration $(r=0)$ cannot be rejected regardless of which test one uses. There was only one exception, when we used the original data (not reported in the paper), and even that was a borderline case. That was Refrigerated 64oz Minute Maid where the "with trend specification" of the trace test perhaps rejects the null of cointegration in favor of one cointegrating vector. The rejection of the null hypothesis was not overwhelming, however: it occurred at 90 percent significance, and only for one specification of the trace test (the "with trend specification"). Moreover, the test statistic value (28.7829) barely exceeded the 90 percent critical value (28.78). Therefore, since the evidence in favor of a cointegration was very weak at best, and in order to treat all series in a similar fashion, we have decided to treat refrigerated $64 \mathrm{oz}$ Minute Maid price as a difference stationary series, like the price series of the remaining eleven products. Consequently, the price and cost series used in this study were all logdifferenced prior to the application of the VAR analysis.

It has been suggested to us that some aspects of pricing decisions which may include advertising, distribution, and other marketing factors, if present, could generate common movement in the cost-price series we analyse. The statistical findings we report in this paper, however, do not suggest a presence of such comovements. First, the heterogeneity in the descriptive statistical measures we report in Tables 1-5 (and which is further discussed below) seems to be inconsistent with a presence of such systematic patterns. Second, from structural point of view, the implication of the finding of non-cointegration is that there are no systematic patterns in the cost-price data we use, that yield a common comovement. Finally, the findings 
reported in section 3.6 below about the absence of any statistically significant within- and cross-equation residual correlations and within and across brands and categories, are consistent with these findings.

Our understanding of the managerial aspects of price change decisions at large US retail supermarket settings are consistent with these findings. First, econometric studies have shown that cross-price elasticities are generally low in this industry (Blattberg and Neslin, 1989) which suggests that there is little benefit in paying attention to other products in a category when changing the price of a single product in the category. Second, the weekly price setting task of the retail supermarket chains such as Dominick's, which according to Levy, et al. (1997) on an average week change prices of about 4,500 of over 25,000 different products they carry, is monumental, and therefore, optimal cross-product price management is unlikely. Third, the sample period covered in this study precedes the current trend in the supermarket industry to think in terms of categories rather than individual products (this is known as "category management").

\subsection{VAR Specification and Residual Correlation Tests}

The lag length, $p$, of the VAR we estimate, was chosen using four lag selection criteria: Final Prediction Error (FPE), Akaike's Information Criterion (AIC), Hannan-Quinn Criterion (HQC), and Schwarz Criterion (SC). The FPE and the AIC indicated optimal lag length of six. The HQC and the SC suggested optimal lag length of two. We have decided to choose a lag length of six since simulation studies cited by Lütkepohl $(1990,1991)$ show that FPE and AIC have better small sample properties in the sense that they choose the correct lag length more often than HQC and SC. Further, larger number of lags reduces the correlation among the VAR residuals. Indeed, the residual correlation analysis results reported below indicate very low correlation values within and across the estimated VAR residual series. This choice may not be costless, however. This is because, as Lütkepohl (1990) shows, if a VAR order is chosen too large, it may result in imprecise coefficient estimates leading to large standard errors of the impulse response and variance decomposition functions.

Table 8 presents the VAR residual correlation analysis results. The first three columns of the table report the results of serial correlation test for each of the three VAR equations. The test statistic we report is the standard Lagrange Multiplier version of Godfrey's test of residual serial correlation, $\chi^{2}(m)$. Along with the statistic values we also report the corresponding $p$-values. We have also computed the $F$-version of the statistic, also known as the modified Lagrange Multiplier test (Harvey, 1981, p. 173), which is equivalent asymptotically to the original Godfrey's test. We do not report it because their results are similar to what we

report here based on the $\chi^{2}$-test. According to the results, neither of the three equations of the VAR generate residuals that exhibit statistically significant serial correlation, as all $p$-vales are higher than 0.10 .

The last three columns of Table 8 present cross-equation residual correlation analysis. Here the point 
estimate is a measure of simple correlation between the residuals of each pair of equations and the figures underneath report the 90 percent probability interval based on resampling method outlined by Leeper and Zha (1999) using 50,000 draws. While the point estimates of the cross-equation residual correlations are low, some confidence intervals are rather wide. Nevertheless, none of the correlation coefficient, even when taking these confidence intervals into account, exceeds 0.20 in absolute value, and most are lower than 0.10. Based on the stationarity, cointegration, and the residual correlation analysis, we conclude, therefore, that the VAR model we estimate is well-specified and so it can be used for structural analysis. ${ }^{24}$

\section{Results on Price Rigidity at the Retail Level}

In section 4.1 we start with a discussion of the first notion of price rigidity. Next, in section 4.2 we study retail price rigidity by examining the dynamic reaction of prices to cost changes, followed by a discussion in section 4.3. Finally, in section 4.4, we evaluate the importance of stages of processing in generating price rigidity by examining whether retailers respond to changes in upstream cost when setting retail prices, followed by a discussion in section $4.5 .^{25}$

\subsection{Measures of retail price rigidity based on frequency of price changes}

Let us consider the first notion of price rigidity by looking at some descriptive statistical measures of the original retail transaction price data. These include sample mean and variance, number of changes, average number of weeks between changes, and average, maximum, and minimum changes in dollars and in percents. Table 4 presents these statistics for the retail prices of refrigerated juice and Table 5 for the retail prices of frozen concentrated juice. All prices and costs in these tables are measured in dollars/oz. According to these tables, the average number of weeks between consecutive price changes for the $64 \mathrm{oz}$ and the $96 \mathrm{oz}$ refrigerated orange juice are about 1.6-2.2 and 2.8-3.8 weeks, respectively. For frozen concentrated orange juice, the average number of weeks between consecutive price changes of 12oz juice (and Tropicana 16oz) is slightly above two weeks. For the $16 \mathrm{oz}$ frozen concentrated juice, the average number of weeks between consecutive price changes is about seven to ten weeks.

This finding, however, is driven primarily by the promotional sales activity which is so prevalent in the retail supermarket industry. To see how these figures would look in the absence of the promotional sale

\footnotetext{
${ }^{24}$ We have also estimated cross-equation correlations across products within the refrigerated and frozen concentrate categories as well as across products within the same brand. These correlations were all small, less than 0.15 (and most less than 0.10 ).

${ }^{25}$ In the discussions that follow we do not present the estimation results for the spot price equation, which is the first equation of the VAR system (1), where the spot price depends only on its own lagged values. This is because understanding the determinants of the spot prices of the orange juice are beyond the scope of this paper. For a study addressing this specific question, see Roll (1984). For the goal of studying the rigidity/flexibility of the wholesale and retail prices, the important point to remember is that spot prices can plausible be thought as being exogenous with respect to the wholesale and retail prices, and the wholesale prices can be thought exogenous with respect to the retail prices. Therefore, we argue, that spot price belongs to the right hand side of the wholesale and retail price equations. The first equation is included in the model only for the sake of simplicity of the formulation of the block recursive system. Since the model is estimated equation by equation, this inclusion does not drive, nor affect, the results we report here for the wholesale and the retail prices.
} 
related price changes, we have reconstructed the "list price" series of the orange juice products by eliminating from the retail transaction prices the discount offered through the sales. The resulting series, a sample of which is shown in Figure 1d, is obviously much smoother, and thus contains fewer and less frequent price changes. We report the above discussed descriptive statistics for the smoothed retail price series in Tables 4 and 5 for refrigerated orange juice and frozen concentrated orange juice, respectively, right underneath the figures calculated for the original non-smoothed series.

In comparison to actual sale price, the smoothed prices are on average higher (row 1) and less volatile (row 2) which is not surprising. Further, for the refrigerated orange juice products (Table 4), the number of price changes during the sample period range between 4-12 for the smoothed series in comparison to 22-51 price changes for the original non-smoothed series. Consequently, the average number of weeks between price changes for the smoothed series ranges between 6.25-20.75 weeks in contrast to the range of 1.63-3.77 weeks for the actual sale price series. For the frozen concentrated orange juice products (Table 5), the number of price changes during the sample period range between 6-9 for the smoothed series in comparison to 28-39 price changes for the original non-smoothed series. Consequently, the average number of weeks between price changes for the smoothed series ranges between 8.66-13.50 weeks in contrast to the range of 2.13-2.96 weeks for the actual sale price series. ${ }^{26}$

These differences underscore the difficulty of determining the importance of the price flexibility we document here when we consider the first notion of price rigidity which relies on the behavior of the price series alone. On one hand, following Carlton (1986), Kashyap (1995), Lach and Tsiddon (1992, 1996), and Warner and Barsky (1995), it may be argued that we should prefer to use the original non-smoothed retail prices as they are the actual transaction prices. On the other hand, it is clear that at least some of the frequent price changes we observe in the data may not be in response to changes in supply or demand conditions and therefore, may not be informative about the extent of price rigidity/flexibility. This conflicting picture makes the evidence reported below on the extent of price reaction to cost changes particularly useful.

\subsection{Cost-based evidence on retail price rigidity}

We begin by presenting VAR estimation results where we study how changes in retailer's costs affect the retail prices over time. The cumulative impulse response functions depicting the dynamic effect of direct cost (i.e., wholesale price) changes on retail prices are shown in the middle panels (b and e) of Figures 2.1-2.6. Figures 2.1-2.3 display the cumulative impulse responses for the refrigerated juice and Figures 2.4-2.6 for the frozen concentrated juice. On each figure, the left hand side column displays the

\footnotetext{
${ }^{26}$ Note that these comparisons exclude frozen concentrated Heritage House and Minute Maid, both 16oz, as these products were not on sale during the sample period and therefore, the smoothing has left the price series of these products unaltered. This is the reason why there are so few price changes during the sample period in the prices of these two products (Table 5, row 3 ). In Figure 1e we show, as an example, the price series of Heritage House, 16oz.
} 
impulse response for the standard size and the right hand side column for the off-standard size. These cumulative impulse response functions represent the cumulative response of the price in dollars to a onedollar shock in the cost.

According to the impulse response functions, the retail prices are flexible in terms of their response to direct cost (i.e., wholesale price) changes. From the middle row of Table 9 we can see that in nine out of twelve cases the retail prices are flexible according to our definition, and in only three cases they exhibit rigidity. As the middle panels of Figures 2.1-2.6 suggest, in many cases the adjustment occurs within three to six weeks from the time the shock occurs. ${ }^{27}$

The variance decomposition results for the retail prices are presented in Figures 2.7-2.12, panels b and e. On each figure, the left hand side column displays the variance decomposition for the standard size and the right hand side column for the off-standard size. According to the plots, the estimated variance decomposition figures tend to settle down at around eight-week lag, supporting our choice of 8th week period as a reasonable cut-off point for specifying the short-run period.

These variance decomposition results are in general consistent with the corresponding impulse response function results. They indicate that in eight of the twelve cases the point estimate of the contribution of the wholesale price innovations to the retail price forecast error variance is between 10 to 35 percent, and statistically significant. In four other cases the variance decomposition indicates small or statistically insignificant effect of wholesale price innovations on retail prices. Thus, the results in general suggest that wholesale prices play a role in the determination of retail prices.

The share of the forecast error variance of each of the three price variables (the spot price, the wholesale price and the retail price) accounted for by its own innovations are not shown to save space. It should be emphasized, however, that these shares are consistently very high, often approaching 90 percent or even more. That is, it is in general true that the overwhelming proportion of the forecast error variance in each of the three dependent variables are due to own innovations. ${ }^{28}$

The results are similar or slightly even stronger when we use moving averaged or smoothed data. For example, according to Table 10 which summarizes the impulse response analysis results for the moving

${ }^{27}$ Once case, refrigerated Heritage House, wholesale-to-retail (64oz), Figure 2.3b, appears to produce anomalous result: the point estimate of the impulse response function is negative for most of the 26-week period. The confidence intervals, however, contains the entire zero line and hence, the true value of the impulse response function statistically does not differ from zero.

${ }^{28}$ From the plots reported in Figures 2.7-2.12, one can easily determine the proportion of the forecast error variance that is accounted for by own innovations. In case of the wholesale prices, that proportion at each time horizon is given by 1.00 minus the proportion of the forecast error variance due to spot price innovations, where the latter is plotted in panel (a) of the figures. For example, according to Figure 2.7a, at the 4-week horizon, the proportion of the forecast error variance that is accounted for by own innovations equals about 97 percent, while at the 8 -week horizon it equals about 82 percent. Similarly, in case of the retail prices, the proportion of the forecast error variance that are accounted for by own innovations at each time horizon equals 1.00 minus the sum of the proportions of forecast error variance due to wholesale and spot price innovations. For example, according to Figures $2.7 \mathrm{~b}$ and $2.7 \mathrm{c}$, for the retail price of $64 \mathrm{oz}$ Tropicana, own innovations account for $1.00-(0.10+0.07)=$ $83 \%$ at the 4 -week horizon and for $1.00-(0.10+0.08)=82 \%$ at the 8 -week horizon. 
averaged data, for ten of the twelve orange juice products retail prices are flexible (five flexible and five tends toward flexible) and only prices of two products exhibit rigidity (and even then, it is the weaker notion of tends toward rigidity). Similarly, according to Table 11 which summarizes the impulse response analysis results for the smoothed data, for eleven of the twelve orange juice products retail prices are flexible (nine flexible and two tends toward flexible) and only the price of one product exhibits rigidity (and even then, it is the weaker notion of tends toward rigidity). ${ }^{29}$

\subsection{Discussion}

In sum, we find that the actual retail transaction prices are very flexible in terms of both notions of price rigidity: (i) they change frequently, and (ii) they respond quickly (often within three to six weeks) and fully to changes in costs. This is an indicator of a remarkable flexibility of retail prices. For comparison purposes, it should be mentioned that Blinder (1994) reports an average lag of three to four months (twelve to sixteen weeks) in the response of prices to cost shocks. Other studies that use micro-level data of final prices, such as Cecchetti (1986) and Kashyap (1995), find even more delayed response of prices to cost shocks. Since our product categories are widely used and representative of many typical retail items, this finding raises the possibility that prices of many other consumer goods which share similarities with the products we study may also exhibit significant flexibility.

We believe that this flexibility is due to the intense competition in the retail market. There are many players in this market and no single chain dominates it. Our retail chain, Dominick's, competes with Jewel, Cub Food, Eagle, Aldi, Walts, and local cooperatives, to name a few. In general, price competition is very intense in this industry (Consumer Reports, 1993), with frequent price wars (Calantone, et al., 1989), and this price competition seems to have escalated over the years in the retail grocery market (Progressive Grocer, 1992 and 1993). The margin for the retailer is small, about one-three percent, which is a further indication of the intensity of competition in this industry (Montgomery, 1994). Theoretical studies show that price flexibility is related to the degree of competition. For example, Dornbusch (1987) shows that a greater degree of price competition will lead to more price flexibility. Thus, the finding of flexibility of retail prices, as measured by their response to changes in direct costs the retailer incurs, may be explained by the highly competitive environment in which the retailer is operating. This explanation is consistent with the results reported by Levy, et al. (1997), who find that supermarket chains of the type studied here each week change prices of as many as 15 percent of the products they carry (prices of about 4,500 of the 25,000 products carried), in spite of the fact that their cost of changing prices comprises over 35 percent of their net margin. ${ }^{30}$

\footnotetext{
${ }^{29}$ Variance decomposition analysis of the original and smoothed data yields results similar to what we report here and therefore, to save space, are excluded from the discussion.

${ }^{30}$ Raju et al. (1990) use micro level transaction price data to address the issue of competition between private labels and national brands. More recent studies by Kadiyali et al. (2000) and Besanko et al. (1999) address retail competition in a structural manner using micro level transaction price data.
} 


\subsection{Further evidence on retail price flexibility and its relation to stages of processing}

We now discuss VAR estimation results where we study how changes in upstream spot commodity costs affect the retail transaction prices over time. According to the estimated impulse response functions, which are reported in the bottom panels of Figures 2.1-2.6, the retail prices tend to be flexible in response to changes in upstream costs. From Table 9 we can see that in ten of the twelve cases retail prices are flexible according to our definition (in seven cases they are strictly flexible, and in three cases they tend towards flexibility) and in only two cases do prices exhibit rigidity (one case of rigidity and one case of tendency towards rigidity). Thus, according to these figures, the retail prices respond to upstream commodity cost changes and the adjustment process is relatively quick, often within four to six weeks.

The impact of the spot price on retail price is also evident if we look at the variance decomposition results reported in panels $\mathrm{c}$ and $\mathrm{f}$ of Figures 2.7-2.12. The figures indicate that between ten to twenty percent of the retail price forecast error variance is due to spot price innovations. With two exceptions, the estimated figures are all statistically significant.

In cases where the contribution of the wholesale price to retail price is small and statistically insignificant, the contribution of the spot price is large and significant, as the plots in panels $\mathrm{c}$ and $\mathrm{f}$ of Figures 2.7-2.12 indicate. Perhaps, the presence of the spot price in the retail price equation is leading to this result. Overall, both costs seem to play some role in the sense that the retailer seems to take both indirect and direct cost changes into account when setting their retail prices. Taken as a whole, the impulse response functions and the variance decomposition results suggest that both the spot costs and wholesale prices affect final retail prices.

The results are similar when we use moving averaged or smoothed data. For example, according to Table 10, for the moving averaged data, for ten of the twelve orange juice products retail prices are flexible (eight flexible and two tends toward flexible) and only prices of two products exhibit rigidity (and even then, it is the weaker notion of tends toward rigid). Similarly, according to Table 11, for the smoothed data, for ten of the twelve orange juice products retail prices are flexible (all flexible and none tends toward flexible) and only the prices of two products exhibit rigidity (one rigid and one tends toward rigid).

\subsection{Discussion}

The findings that downstream prices respond to upstream cost changes is one of the most striking finding of this study. These findings can be related to the role of stages of processing in price flexibility. Studies, for example, Taylor (1980), Blanchard (1983), Mankiw (1985), Gordon (1990), Blinder (1994), Basu (1995), Clark (1999), and Huang and Liu (2001), have shown that markets with vertical hierarchical structure may exhibit slow adjustment process of prices to cost shocks originating upstream. We find that 
this does not really happen in our data in spite of the fact that the market we study has a clear vertically hierarchical structure, spot-to-wholesale-to-retail. We believe this is because we study individual products which are produced using only few inputs and which flow through only two stages of processing. Gordon (1990) suggests, in such an environment a quick response of price is expected. The stages-of-processing model of Blanchard (1983) makes a similar prediction: the smaller the number of stages of processing, the more flexible prices are. The market we study consists of only two stages, which does not seem to be a sufficient barrier to retail price adjustments.

A possible explanation for this finding is that the information of cost changes that occur upstream are readily available to retail price setters. This is because the behavior of frozen concentrate orange juice contract prices at the NYCE are published daily in the general financial media. The big commodity cost increase observed in our data during December 1989 (observations 16-20) was caused by a freeze in Florida which significantly damaged not only the fruit on trees, but also the trees themselves. The damage was so big that Florida Governor in December 29, 1989 declared entire state of Florida a disaster area. This freeze made national headlines and therefore, it is likely that the average consumer was also aware of it (Levy, et al., 2001).

\section{Results on Price Rigidity at the Manufacturer Level}

In this section we start with a discussion of the findings based on the first notion of price rigidity in section 5.1. Next, in section 5.2 we study intermediate goods price rigidity by examining the dynamic reaction of wholesale prices to commodity cost changes, followed by a discussion in section 5.3.

\subsection{Measures of wholesale price rigidity based on frequency of price changes}

Tables 2 and 3 present descriptive statistical measures for the original wholesale transaction prices of refrigerated and frozen concentrated orange juice, respectively. According to the tables, the average number of weeks between consecutive price changes of $64 \mathrm{oz}$ and $96 \mathrm{oz}$ refrigerated juice are between 1.5-2.1 and 1.8-3.9 weeks, respectively. For frozen concentrated orange juice, the average number of weeks between consecutive price changes of $12 \mathrm{oz}$ juice is about 2-3 weeks, with the exception of Tropicana 12oz whose price seems to change every 4-5 weeks. For the $16 \mathrm{oz}$ juice, the average number of weeks between consecutive price changes is about 3-6 weeks, with the exception of Tropicana 16oz whose price seems to change every 12 weeks. $^{31}$

Thus, judging from such frequent changes, the wholesale prices of orange juice, at least of the standard size, are also very flexible, especially in comparison to the figures cited in other studies of intermediate goods prices for other product categories. For example, Carlton (1986) finds that prices of

\footnotetext{
${ }^{31}$ At the wholesale level there is little visible promotional sales activity, and therefore we have not considered smoothing of the wholesale price series.
} 
various types of intermediate goods in many manufacturing industries remain unchanged for almost a year and sometimes even longer. According to Blinder (1994), 55 percent of the firms in his sample change prices no more than once a year.

\section{2. $\quad$ Cost-based Evidence on Wholesale Price Rigidity}

Now we present VAR estimation results where we study how changes in spot commodity costs affect the wholesale prices over time. The cumulative impulse response functions depicting the dynamic effect of spot commodity cost changes on wholesale prices are shown in the top panels (a and d) of Figures 2.1-2.6. According to the impulse response functions, the wholesale price tends to be less flexible in response to cost changes in comparison to the retail price. According to Table 9 in six of the twelve cases wholesale prices are rigid in the short run according to our definition, and in six cases they are flexible. Thus, according to the impulse response functions, wholesale prices of one half of the products studied here do not respond fully to changes in commodity cost. The extent of the price rigidity found in this channel is particularly significant for frozen Tropicana, Figures 2.4a and 2.4d. In sum, the impulse response functions at this channel suggest that at the manufacturing level more prices are rigid in comparison to the retail level.

The results of variance decomposition reported in panels a and d of Figures 2.7-2.12 indicate that in five of the twelve cases the contribution of the spot price innovations to the wholesale price forecast error variance is small and statistically insignificant. In the remaining seven cases the figures indicate a relatively large and statistically significant effect. The small and statistically insignificant effect of spot cost on the wholesale price for Frozen Tropicana, Figures 2.10a and 2.10d, is evident here too.

The results are similar when we use moving averaged or smoothed data. For example, according to Table 10, for the moving averaged data, for only four of the twelve orange juice products retail prices are flexible (all flexible) while prices of eight products exhibit rigidity (five rigid and three tends toward rigid). Similarly, according to Table 11, for the smoothed data, for six of the twelve orange juice products retail prices are flexible (all flexible) and the prices of the remaining six products exhibit rigidity (five rigid and one tends toward rigid).

\subsection{Discussion}

Perhaps the most interesting finding in this section is that we find evidence of more price rigidity in response to cost shocks in the intermediate goods level of the market. This, even though wholesale prices change frequently and therefore exhibit flexibility according to the first measure of price rigidity. Our evidence provides support for Warner and Barsky's (1995) contention that the mere finding of individual price volatility is not inconsistent with the existence of price rigidities. There may, in fact, be interesting aspects of price rigidity in markets where prices do change frequently. At a minimum, this suggests the importance of defining and measuring price rigidity in terms of price response to cost or demand changes as 
suggested by Blinder (1991) and Carlton and Perloff (1994).

This price rigidity can be explained by the limited degree of competition, and the extent of contracting and long term relationships found in these markets. There are few national brands that control significant shares of the orange juice market. For example, during 1991, the market share of Tropicana was $21.6 \%$ and that of Minute Maid was 21.4\% (Freedman, 1991), while the rest of the market was shared by private labels and smaller brands. Ward and Kilmer (1989, p. 41) state that, "data on the market structure ... indicate that the industry is oligopolistic." This suggests that the manufacturer level of the channel is less competitive in comparison to the retail level of the channel, and therefore should exhibit more price rigidity.

A presence of long-term explicit nominal contracts can also lead to the price rigidity in this market (Fischer, 1977; Taylor, 1980). In the frozen concentrated orange juice market, the manufacturers of national brands often have long-term contractual arrangements with their suppliers (Freedman, 1991). For example, "A common practice among many manufacturers and retail chains is to establish verbal contracts to purchase a fixed supply of private label citrus over the season" (Ward and Kilmer, 1989, p. 49). Similarly, "A large share of brand sales are made through contractual arrangements with the major food retail chains" (Ward and Kilmer, 1989, p. 36). Thus, the existence of these contracts may also help explain the rigidity we observe at this level of the channel. In contrast, no such explicit contracts exist between retailers and their customers. Therefore, we would expect to find more rigidity at the manufacturing level in comparison to the retail level.

The orange juice manufacturers studied here have long term relationships with retailers which could be another source of price rigidity. For example, according to Ward and Kilmer (1989), long term relationships are an important aspect of transactions between these manufacturers and retailers. ${ }^{32}$ The finding of rigidity at the manufacturing level should not be surprising since it is an intermediate goods market. In his study of intermediate goods transactions prices, Carlton (1986) also finds significant price rigidity and suggests that these long term relationships can contribute to price rigidity. Williamson (1975) also states that the impediment to changing price may be that the buyer or seller could feel the other side is taking advantage of him. Okun $(1975,1981)$ and Haddock and McChesney (1994) also suggest the importance of these kinds of considerations. In contrast, individual long-term relationships are not as common between large supermarket retailers and their customers. Given the volume of sales and the large number of customers the retailers serve, it is difficult to individualize these relationships. Therefore, we would expect to find more rigidity at the manufacturing level in comparison with the retail level.

\footnotetext{
${ }^{32}$ One advantage of such a long-term relationship for retailers is that retail buyers are often eligible to purchase given amounts of a product for a specified period of time at the previous or lower price, after announcement of wholesale price increase. The extent of this "buy-in privilege" is a function of the retailers purchase record and of the extent of the relationship between the retailer and manufacturer. The buy-in option allows the retailer to plan ahead with respect to advertising campaigns, pricing decisions, special promotions, and inventory management (Ward and Kilmer, 1989).
} 


\section{Conclusions}

In this study we empirically examine the extent of price rigidity in two consumer good product categories for twelve individual products using a unique data set that consists of retail prices, wholesale

prices, and manufacturers' costs. We find that retail transaction prices exhibit flexibility in terms of both notions of price rigidity considered in this paper: they change frequently, and they respond quickly and fully to changes in costs. Moreover, we find that retail prices respond not only to direct costs, but also to upstream costs which further reinforces the degree of retail price flexibility. This is a significantly greater degree of price flexibility than has been reported in the existing studies of final good prices and suggests that retail price flexibility may be more prevalent than currently believed. The finding that stages of processing do not inhibit price flexibility for these products is important because the existing theoretical models of price adjustment usually do not consider this kind price response to indirect or upstream cost shocks. This also suggests that more empirical work needs to be done using micro level data with explicit consideration of the interactions between multiple levels of the channel through which products flow.

At the manufacturing level we find evidence that wholesale prices may be more rigid than appears on the surface. Specifically, we find that even though wholesale prices change frequently, they still exhibit rigidity in reaction to cost changes. This suggests that price rigidity may be an important phenomenon even under conditions of changing prices, and echoes Warner and Barsky's (1995) suggestion that the mere finding of individual price volatility is not inconsistent with the existence of price rigidities. This raises the possibility that price rigidity may be hiding under the surface of many markets that may seem at first glance flexible. At a minimum, this finding suggests the importance of defining and measuring price rigidity as price responses to cost or demand changes.

Finally, we find a wide variation in the degree of price rigidity, from rigidity in wholesale prices all the way to flexibility in retail prices. We explain this variation by documenting the differences in the competitive, contracting, and long-term relationship structures of these two levels of the channel. This variation suggests that the theoretical assumptions of complete price rigidity or complete price flexibility made in many widely used models may not be accurate characterization of all markets. Therefore, at the theoretical level, macroeconomic models which allow prices of some goods to be rigid and others-flexible, as recently done, for example, by Ohanian and Stockman (1994a, 1994b) may be a promising route to pursue. At the empirical level, this variation suggests the importance of studying heterogeneity in price rigidity to determine which industries, and which markets have rigid/flexible prices.

An important limitation of this study should be pointed out. One of the unique advantages of this study is the data set it uses which includes the actual transaction prices at the retail and wholesale level on a weekly basis which matches the supermarkets' weekly price adjustment cycle. However, for the purpose of 
answering some key macroeconomic questions which relate to business cycles, this advantage is perhaps also the study's greatest disadvantage. This is because the price rigidity/flexibility phenomena we are documenting occur at an incredible high frequency, over a period of 4-8 weeks only, while macroeconomists that study business cycles naturally focus on the phenomena of price rigidity/flexibility that hold over the business cycle, which typically are identified as 3-8 year cycles. In this sense, the frequency of the data we use is perhaps too high and at this stage, there are no practical ways of resolving this difficulty because the time-span these and other similar scanner data sets cover is rather short (relative to the time-span, few decades at least, we would want to cover) to study business cycles, as scanner data set collection and especially its mass storage has began only recently. As discussed in the introduction, the goal of this study and the results we report are nevertheless valuable for the understanding of the phenomenon of individual price rigidity/flexibility and its empirical significance.

Our findings point to various questions for which this type of data can be particularly useful. For example, the finding that retail prices respond not just to their direct costs but also to these upstream manufacturers' costs reinforces the results on retail price flexibility, and suggests that it is important to view prices in the context of all costs, both direct and indirect, to fully understand the response of prices to cost or demand shocks. Therefore, more empirical work is needed to fully explore the interactions between multiple levels of the market through which products flow using other micro level data sets with particular attention to the content of the information set that price setters have at different levels, as suggested by Blanchard (1987), Gordon (1990), and Meltzer (1994). We only study the cost-price relationship for two product categories and for a single retail chain. The product categories we study (frozen concentrate and refrigerated orange juice) are widely used and representative of many typical retail items. Further, the pricing practices of Dominick's retail chain are representative of many large U.S. retail grocery chains. Nevertheless, future research should examine these issues across other product categories and other retail stores (Müller, et al., 1997; Chevalier, et al., 2000; Barsky, et al., 2001; Feenstra and Shapiro, 2001). An additional question one could study with our data is how prices respond to cumulative cost changes, as, for example, in Cecchetti (1986). Also, the data set of the type used here can be used to evaluate which of the existing theories of cost of changing price (e.g., fixed cost vs convex cost) fits the retail market we study best, as, for example, in Sheshinski, Tishler, and Weiss (1981), Lieberman and Zilberfarb (1985), Danziger (1987), Rotemberg (1987), and Kashyap (1995). At the theoretical level, the finding that prices may be responding not only to direct costs but also to upstream costs, suggests that studying models which accommodate such an indirect cost-shock passthrough may be a potentially fruitful research direction to pursue. 


\section{References}

Allenby, Greg M. and Peter E. Rossi, 1991, Quality perceptions and asymmetric switching between brands, Marketing Science 10 (3), 185-204.

Ball, Laurence and N.Gregory Mankiw, 1994, A sticky-price manifesto, Carnegie-Rochester Conference Series on Public Policy, December, 127-152.

Ball, Laurence and N.Gregory Mankiw, 1995. Relative price changes as aggregate supply shocks. Quarterly Journal of Economics 110, 161-193.

Barsky, Robert, Mark Bergen, Shantanu Dutta, and Daniel Levy, 2001, What can the price gap between branded and generic tell us about markups? In Scanner Data and Price Indexes, edited by Robert Feenstra and Matthew Shapiro, (National Bureau of Economic Research and the University of Chicago Press, Chicago, IL), forthcoming; also circulated as NBER Working Paper No. 8426.

Basu, Susanto, 1995, intermediate goods and business cycles: implications for productivity and welfare, American Economic Review 85, No. 3, 512-531.

Baur, Robert F. and Peter F. Orazem, 1994, the rationality and price effects of u.s. department of agriculture forecasts of oranges, Journal of Finance, Volume XLIX, No. 2, June, 681-695.

Besanko, D. S., S. Gupta, D. Jain, 1999, Logit demand estimation under competitive pricing behavior: an equilibrium framework, Management Science 38, 1732-1749.

Blanchard, Olivier J., 1983, Price asynchronization and price-level inertia, in R. Dornbusch and M.H. Simonsen, eds., Inflation, Debt, and Indexation (The MIT Press, Cambridge, MA), 3-24.

Blanchard, Olivier J., 1987, Aggregate and individual price adjustment, Brookings Papers on Economic Activity 1, 57-109.

Blattberg, R. and S. Neslin, 1989, Sales Promotion (Prentice Hall, Englewood Cliffs, NJ).

Blattberg Robert C., and Ken Wisniewski, 1989, Price induced patterns of competition, Marketing Science $8,291-310$.

Blinder, Alan S., 1982, Inventories and sticky prices: more on microfoundations of macroeconomics, American Economic Review 72, June, 334-348.

Blinder, Alan S., 1991, Why are prices sticky? Preliminary results from an interview study, American Economic Review, Volume 81, 89-96.

Blinder, Alan S., 1994, On sticky prices: academic theories meet the real world, in N. Gregory Mankiw ed., Monetary Policy (University of Chicago Press and National Bureau of Economic Research, Chicago, IL), 117-150. 
Borenstein, Severin, A. Colin Cameron, and Richard Gilbert, 1992, Asymmetric gasoline price responses to crude oil price changes, Working Paper, University of California, Davis.

Borenstein, Severin and Andrea Shepard, 1995, Sticky prices, inventories, and market power in gasoline market, Working Paper.

Bresnahan, Timothy F., 1989, Industries with market power, in Handbook of Industrial Organization, edited by R. Schmalensee and R.D. Willig (North Holland, Amsterdam), 1011-1057.

Cagan, Phillip, 1974, The hydra-headed monster: the problem of inflation in the United States, Domestic Affairs Study No. 26 (Washington, DC: American Enterprise Institute).

Calantone, Roger J., et al., 1989, Flanking in a price war, Interfaces 19, March-April, 1-12.

Caplin, Andrew, 1993, Individual inertia and aggregate dynamics, in E. Sheshinski and Y. Weiss, ed., Optimal Pricing, Inflation, and the Cost of Price Adjustment (The MIT Press, Cambridge, MA), 19-45.

Carlton, Dennis, 1986, The Rigidity of prices, American Economic Review 76, September, 637-658.

Carlton, Dennis, 1989, The theory and the facts of how markets clear, in Handbook of Industrial Organization, Volume 1, edited by R. Schmalensee and R. Willig (North Holland, Amsterdam), 909-946.

Carlton, Dennis and Jeffrey M. Perloff, 1994, Modern Industrial Organization (Harper Collins, New York, NY).

Carpenter, G. S. and D. R. Lehmann, 1985, A Model of marketing mix, brand switching and competition, Journal of Marketing Research, 22, 318-329.

Cecchetti, Stephen G., 1986, The Frequency of price adjustment: a study of the newsstand prices of magazines, Journal of Econometrics, Volume 31, April, 255-274.

Chevalier, Judith A., 1995, Capital structure and product market competition: empirical evidence from supermarket industry, American Economic Review 85, No. 3, 415-435.

Chevalier, Judith, Anil Kashyap, and Peter Rossi, 2000, Why don't prices rise during peak demand periods? Evidence from scanner data. National Bureau of Economic Research Working Paper No. 7981, October.

Chintagunta, P., D. Jain, and N. Vilcassim, 1991, Investigating heterogeneity in brand preferences in logit models for panel data, Journal of Marketing Research, 28, November, 417-428.

Clark, Todd E., 1999, The responses of prices at different stages of production to monetary policy shocks, Review of Economics and Statistics 81, 420-433. 
Danziger, Leif, 1987, Inflation, fixed cost of price adjustments, and measurement of relative price variability, American Economic Review, Volume 77, No. 4, September, 704-713.

Dhar, Sanjay and Stephen J. Hoch, 1997, Why store brand penetration varies by retailer, Marketing Science, 16,3, 208-227.

Dornbusch, Rudiger, 1987, Exchange rates and prices, American Economic Review 77, 93-106.

Dutta, Shantanu, Mark Bergen, Daniel Levy, and Robert Venable, 1999, Menu costs, posted prices, and multiproduct retailers, Journal of Money, Credit, and Banking, 31 (4), November, 683-703.

Fama, Eugene F. and Kenneth R. French, 1987, Commodity futures prices: some evidence on forecast power, premiums, and the theory of storage, Journal of Business 60, No. 1, 55-73.

Feenstra, Robert and Matthew Shapiro, eds., Scanner Data and Price Indexes (National Bureau of Economic Research and the University of Chicago Press, Chicago, IL), 2001, forthcoming.

Fischer, Stanley, 1977, Long-term contracts, rational expectation, and the optimal money supply rule, Journal of Political Economy 85, No. 1, 191-205.

Freedman, A., 1991, Tropicana officials fired by Seagram kept quiet about $\$ 20$ mil. overrun, The Wall Street Journal, September 24, 24.

French, K.R., 1986, Detecting spot price forecasts in futures prices, Journal of Business 59, S39-S54.

Gilchrist, S.G., Zakrajsek, E., 1995, The importance of credit for macroeconomic activity: identification through heterogeneity, Conference Series 39. Boston: Federal Reserve Bank of Boston, 129-58.

Gonzalo, J., 1989, Comparison of five methods of estimating long-run equilibrium relations, University of California, San Diego, Working Paper No. 55.

Gonul, Fusun and Kannan Srinivasan, 1993, Modeling multiple sources of heterogeneity in multinomial logit models: methodological and managerial issues, Marketing Science,12(3), 213-229.

Gordon, Robert, 1990, What is new-Keynesian economics? Journal of Economic Literature 28, 1115-1171.

Gupta, Sunil, 1988, Impact of sales promotion on when, what and how much to buy, Journal of Marketing Research, 25, 342-356.

Haddock, David D. and Fred S. McChesney, 1994, Why do firms contrive shortages? the economics of intentional mispricing, Economic Inquiry 32, No. 4, October, 562-581.

Hannan, T. and A. Berger, 1991, The Rigidity of prices: evidence from the banking industry, American 
Economic Review 81, No. 4, September, 938-945.

Harvey, A.C., 1981, The Econometric Analysis of Time Series (Philip Allan, London).

Hoch, Stephen J., Byung-Do Kim, Alan L. Montgomery, and Peter Rossi, 1995), Determinants of store level price elasticity, Journal of Marketing Research, 31,1, 17-29.

Huang, K.X.D, Liu, Zheng, 2001, Production chains and general equilibrium aggregate dynamics, Journal of Monetary Economics, forthcoming.

Johansen, S., 1988, Statistical analysis of cointegrated vectors, Journal of Economic Dynamics and Control, 12, 231-54.

Johansen, S. and K. Juselius, 1990, Maximum likelihood estimation and inference on cointegration, Oxford Bulletin of Economics and Statistics 52 (2), 169-210.

Kadiyali, Vrinda, Pradeep Chintagunta and Naufel Vilcassim, 2000, Manufacturer-retailer channel interactions and implications for channel power: an empirical investigation of pricing in a local market, Marketing Science, 19, 2, 127-148.

Kamakura, Wagner A. and Gary J. Russell, 1989, A probabilistic choice model for market segmentation and elasticity structure, Journal of Marketing Research 26, November, 379-390

Kashyap, Anil K., 1995, Sticky prices: new evidence from retail catalogues, Quarterly Journal of Economics, Volume 110, No. 1, February, 245-274.

Krishnamurthi, Lakshman and S.P. Raj, 1988, A model of brand choice and purchase quantity price sensitivities, Marketing Science, 7, 1-20.

Lach, Saul and Daniel Tsiddon, 1992, The behavior of prices and inflation: an empirical analysis of disaggregated data, Journal of Political Economy, 100, No. 2, 349-389.

Lach, Saul and Daniel Tsiddon, 1996, Staggering and synchronization in price setting: evidence from multiproduct firms, American Economic Review, Volume 86, No. 5, 1175-96.

Lattin, J.M. and R.E. Bucklin, 1989, Reference effects of price and promotion on brand choice behavior, Journal of Marketing Research, 26, 299-310.

Leeper, Eric M. and Tao Zha, 1999, Modest policy interventions, Federal Reserve Bank of Atlanta, Working Paper, 99-22.

Levy, Daniel, Mark Bergen, Shantanu Dutta, and Robert Venable, 1997, The magnitude of menu costs: direct evidence from large u.s. supermarket chains, Quarterly Journal of Economics, Vol. 112 (3), 791-825. 
Levy, Daniel, Shantanu Dutta, and Mark Bergen, 2001, Heterogeneity in price rigidity: evidence from a case study using micro-level data, Journal of Money, Credit, and Banking, forthcoming.

Levy, Daniel, Shantanu Dutta, Mark Bergen, and Robert Venable, 1998, Price adjustment at multiproduct retailers, Managerial and Decision Economics, 19 (2), March, 81-120.

Lieberman, Yehoshua and Ben-Zion Zilberfarb, 1985, Price adjustment strategy under conditions of high inflation: an empirical examination, Journal of Economics and Business 37, 253-265.

Lütkepohl, Helmut, 1990, Asymptotic distributions of impulse response functions and forecast error variance decompositions of VAR models, Review of Economics and Statistics, Volume 72, 116-125.

Lütkepohl, Helmut, 1991, Introduction to Multiple Time Series Analysis (Springer-Verlag, Berlin).

Mankiw, N. Gregory, 1985, Small menu costs and large business cycles: a macroeconomic model of monopoly, Quarterly Journal of Economics, Volume 100, May, 529-539.

Mankiw, N. Gregory and David Romer, 1991, New Keynesian Economics, Volumes 1 and 2 (The MIT Press, Cambridge, MA).

Meltzer, Allan H., 1995, Information, sticky prices, and macroeconomic foundations, Federal Reserve Bank of St. Louis Review, Volume 77, No. 3, June, 101-118.

Montgomery, A., 1994, The Impact of micro-marketing on pricing strategy, Ph.D. Thesis, Department of Marketing, Graduate School of Business, University of Chicago.

Müller Georg, Mark Bergen, Shantanu Dutta, and Daniel Levy, 1997, Price rigidity during holiday periods: the role of menu costs, Working Paper, presented at the January 1998 American Economics Association Meeting, Chicago, IL.

Neumark, David and Steven A. Sharpe, 1993, Market structure and the nature of price rigidity: evidence from the market for consumer deposits, Quarterly Journal of Economics 108, 657-680.

Ohanian, L. and A. Stockman, 1994a, How much price stickiness is necessary for reasonable liquidity effects? Working Paper.

Ohanian, L. and A. Stockman, 1994b, Short-run effects of money when some prices are sticky, Economic Quarterly, Federal Reserve Bank of Richmond, 80 (3), Summer,1-23.

Okun, Arthur M., 1975, Inflation: its mechanics and welfare costs, Brookings Papers on Economic Activity 2, 351-390.

Okun, Arthur M., 1981, Prices and Quantities: A Macroeconomic Analysis (The Brookings Institution, Washington, DC). 
Osterwald-Lenum, M., 1992, A note on quantiles and asymptotic distribution of the maximum likelihood cointegration rank test statistics, Oxford Bulletin of Economics and Statistics 54, 461-471.

Pagan, Adrian R., 1995, Three econometric methodologies: an update, in Surveys in econometrics, edited by L. Oxley, D.A.R. George, C.J. Roberts, and S. Sayer (Blackwell Publishers, Cambridge, MA), 30-41.

Podivinsky, J., 1990, Testing misspecified cointegrating relationships, Monash University .

Raju, Jagmohan S., Raj K. Sethuraman and Sanjay K. Dhar, 1995, The introduction and performance of store brands, Management Science, 41, June, 957-978.

Raju, Jagmohan S., V. Srinivasan and Rajiv Lal, 1990, The effects of brand loyalty on competitive price promotional strategies, Management Science, 36 (March), 276-304.

Roll, Richard, 1984, Orange juice and weather, American Economic Review 74, 861-880.

Rotemberg, Julio J., 1987, The new Keynesian microfoundations, National Bureau of Economic Research Macro Annual, 69-104.

Schmittlein, David C., Lee G. Cooper, and Donald Morrison, 1993, Truth in concentration in the land of 80/20 laws, Marketing Science, 12, 2, 167-183.

Sheshinski, Eytan, Asher Tishler, and Yoram Weiss, 1981, Inflation, cost of price adjustment, and the amplitude of real price changes: an empirical analysis, in Development in an Inflationary World, edited by J. Flanders and A. Razin (Academic Press, New York, NY), 195-207.

Sims, Christopher A. and Tao Zha, 1999, Error bands for impulse responses, Econometrica 67(5), 1113-1155.

Steckel, J. H. and W. R. Vanhonacker, 1988, A heterogeneous conditional logit model of choice, Journal of Business and Economics Statistics, 6, 3, 391-398.

Stigler, George J. and James K. Kindahl, 1970, Behavior of Industrial Prices (University of Chicago and National Bureau of Economic Research, New York, NY).

Stiglitz, Joseph, 1984, Price rigidities and market structure, American Economic Review 74, 350-355.

Taylor, John B., 1980, Staggered wage setting in a macro model, American Economic Review 69, $108-13$.

Taylor, John B., 2000, Low inflation, pass-through, and the pricing power of firms, European Economic Review 44, 1389-1408.

Villas-Boas, J. Miguel and R. S. Winer, 1999, Endogeneity in brand choice models, Management Science, 45, 1324-1338. 
Ward, R. and R. Kilmer, 1989, The Citrus Industry: A Domestic and International Perspective (Iowa State University Press, Ames, Iowa).

Warner, Elizabeth and Robert Barsky, 1995, The timing and magnitude of retail store markdowns: evidence from weekends and holidays, Quarterly Journal of Economics, 110 (2), 321-352.

Weiss, Yoram, 1993, Introduction, in Optimal Pricing, Inflation, and the Cost of Price Adjustment, edited by Eytan Sheshinski and Yoram Weiss (The MIT Press, Cambridge, MA), 3-17.

Williamson, Oliver E., 1975, Markets and hierarchies (Free Press, New York, NY).

Wynne, Mark A., 1995, Sticky prices: what is the evidence? Federal Reserve Bank of Dallas Economic Review, First Quarter, 1-12.

Zha, Tao, 1999, Block recursion and structural vector autoregressions, Journal of Econometrics 90 (2), 291-316. 
Figure 1a. Schematic Description of the Florida Frozen Concentrated Orange Juice Market

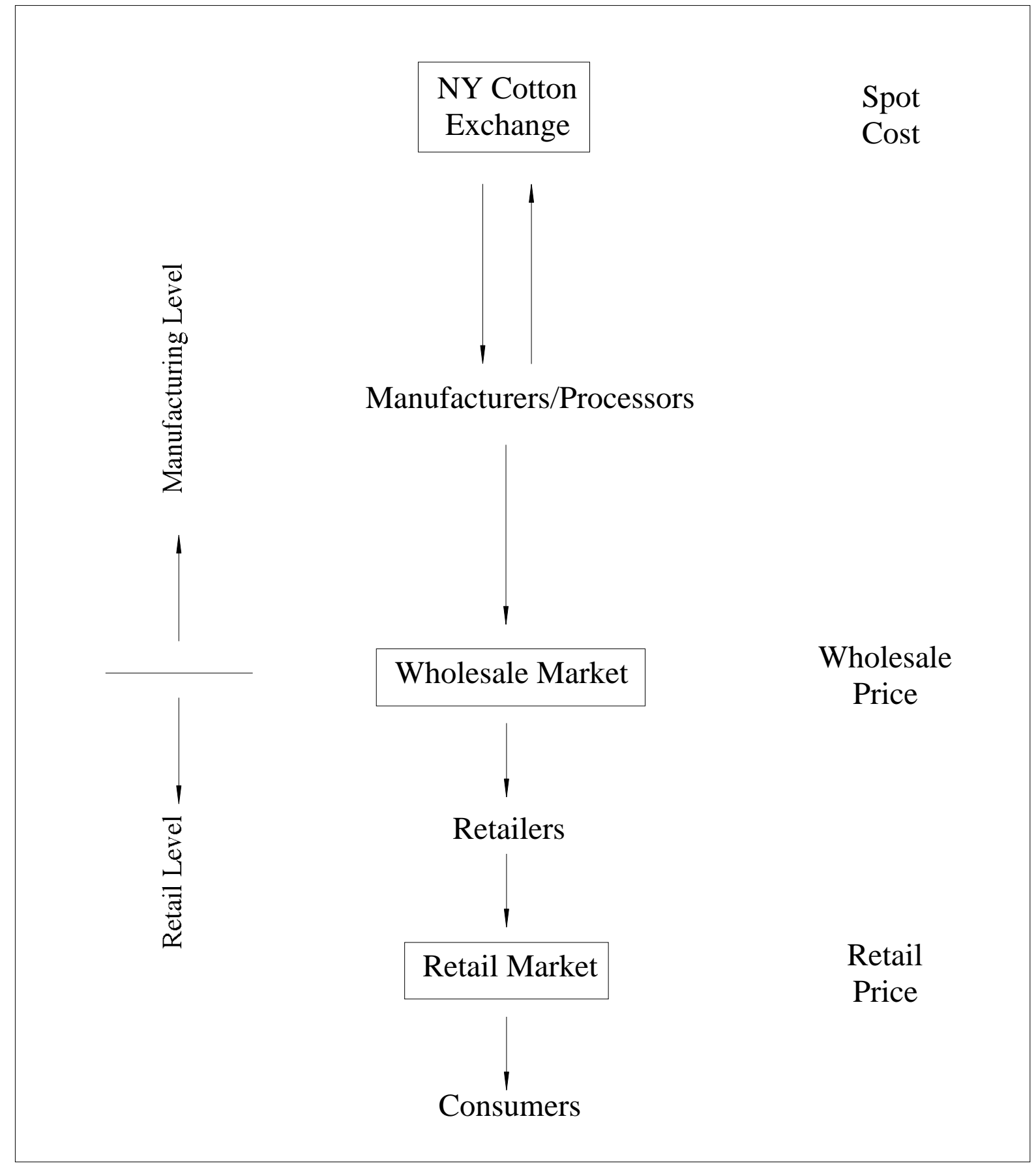

Note: This chart is a simplified description of the organizational structure of the Florida orange juice market. Orange juice growers sell the fruit to orange juice manufacturers/processors who convert the oranges into frozen concentrate. There are two types of processors: one group of processors are privately owned and produce orange juice for private label. The other group of processors are owned by national orange juice manufacturers like Tropicana and Minute Maid, and they produce nationally branded products. The manufacturers/processors package and sell the concentrated juice to retailers, either in its frozen form or reconstituted from concentrate and packaged as refrigerated juice. Oranges are also sold for other uses such as for preparing freshly-squeezed juice, for table use, for producing food additives, and so forth through other channels of distribution. These additional uses and their associated channels are not shown on the chart since in this paper we only study the market for frozen concentrated and refrigerated (reconstituted from frozen concentrated) orange juice. See Ward and Kilmer (1989) for details. 
Fig. 1b. Cost and Price Series of Frozen Heritage House, 12oz (dollars/oz)

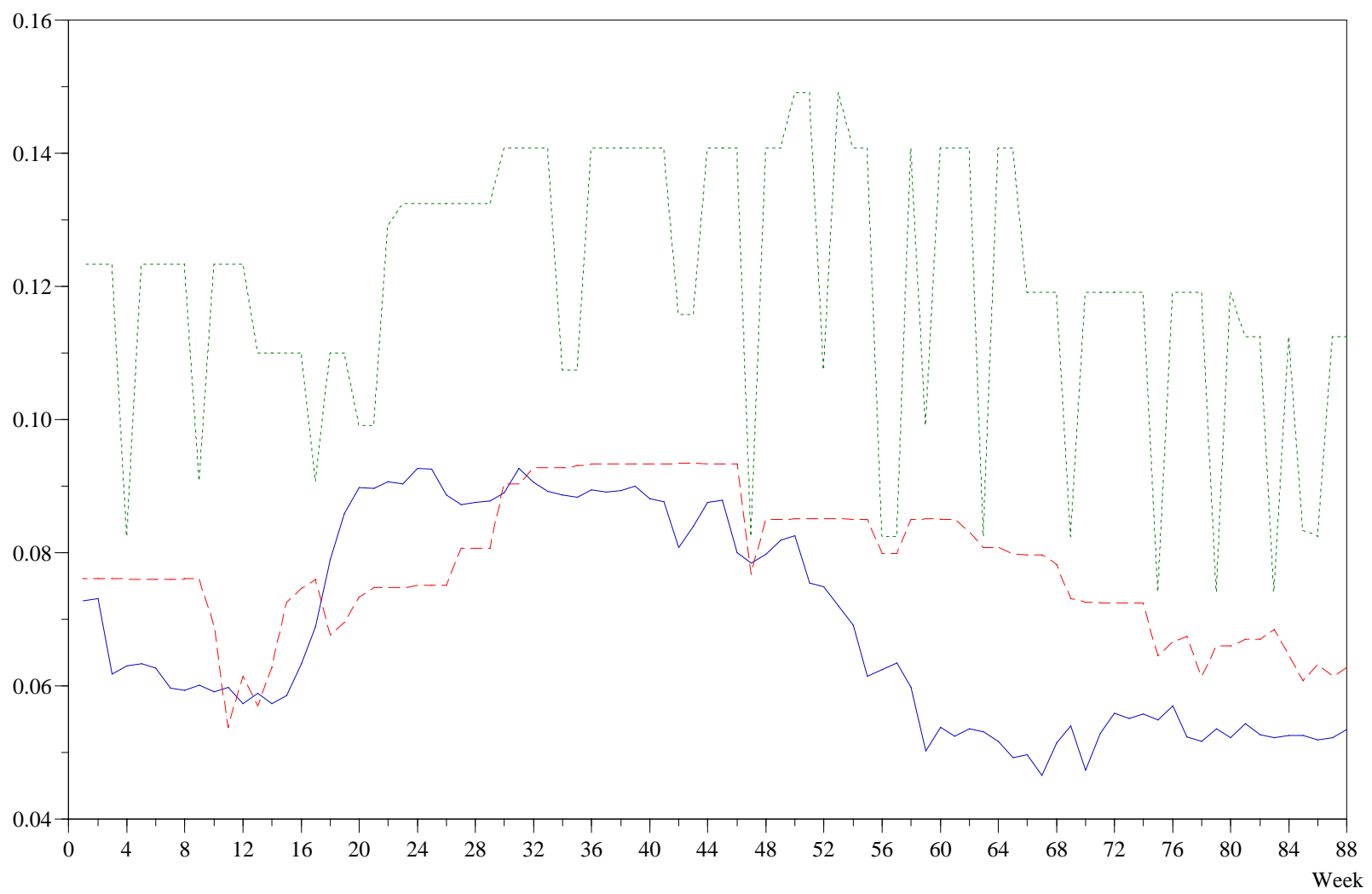


Fig. 1c. Cost and Price Series of Frozen Heritage House, 12oz, Moving Averages (dollars/oz)

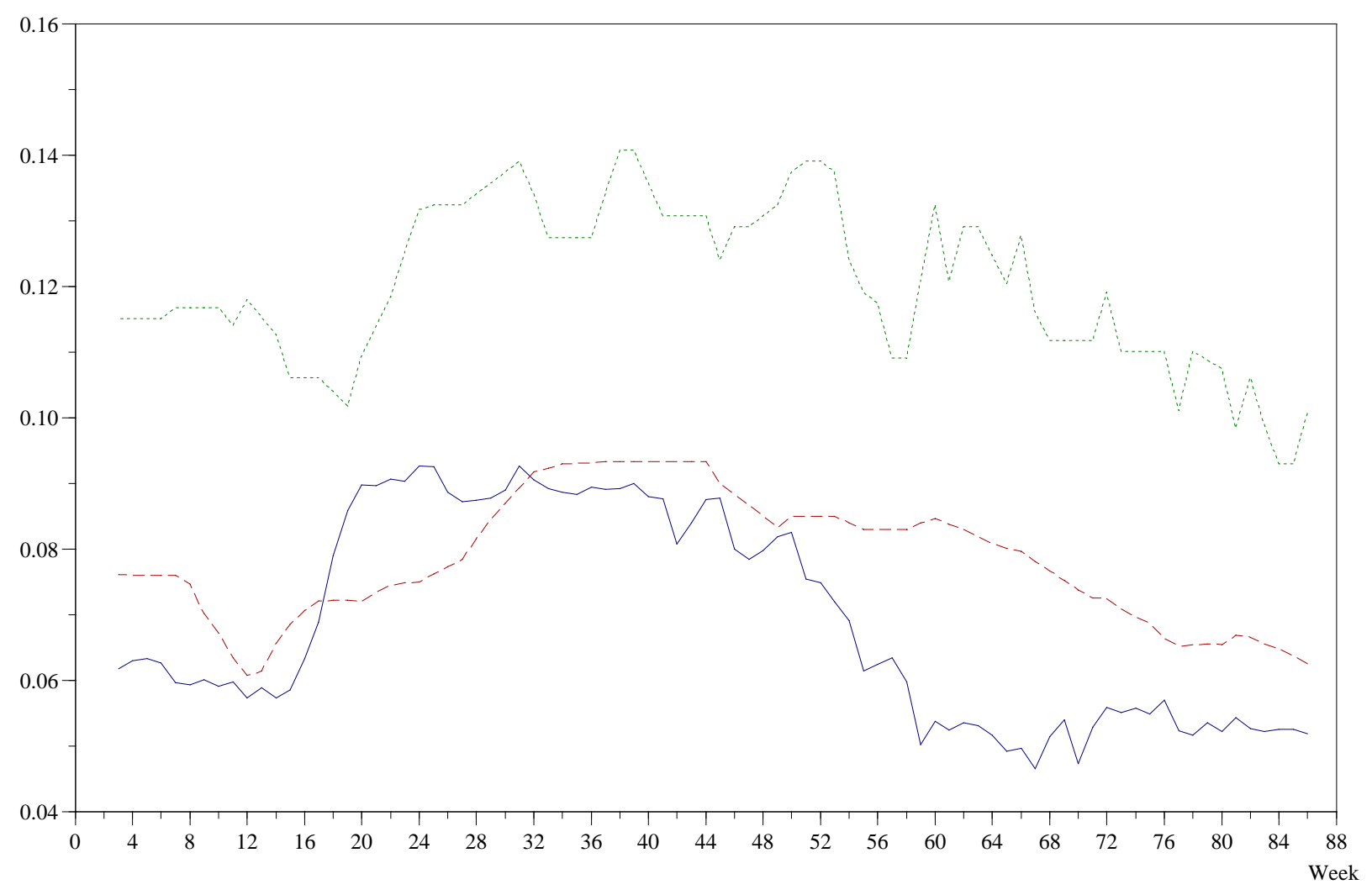


Fig. 1d. Smoothed and Original Retail Price Series of Frozen Heritage House, 12oz (dollars/oz)

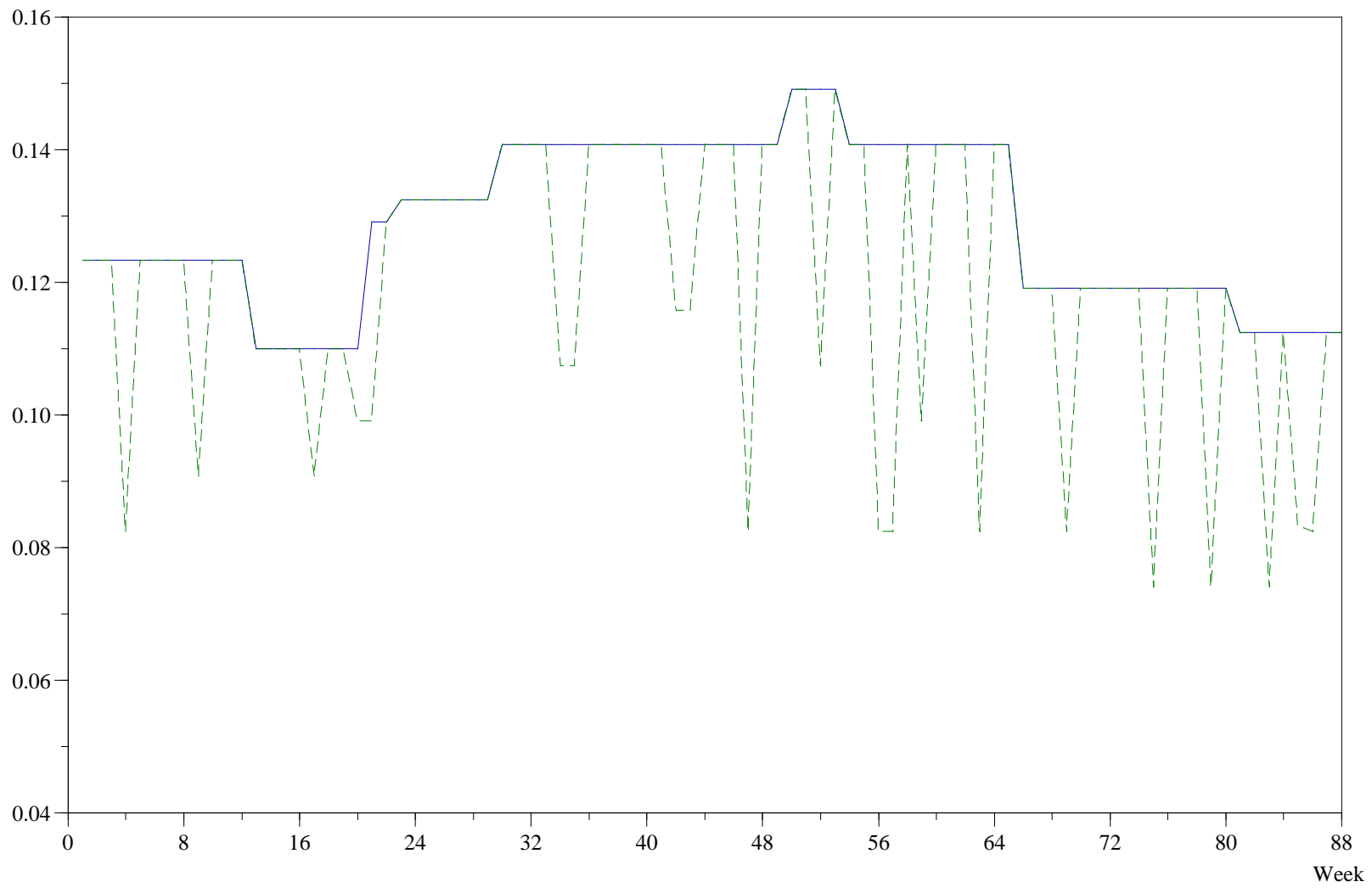


Fig. 1e. Original Retail Price Series of Frozen Heritage House, 12oz (dollars/oz)

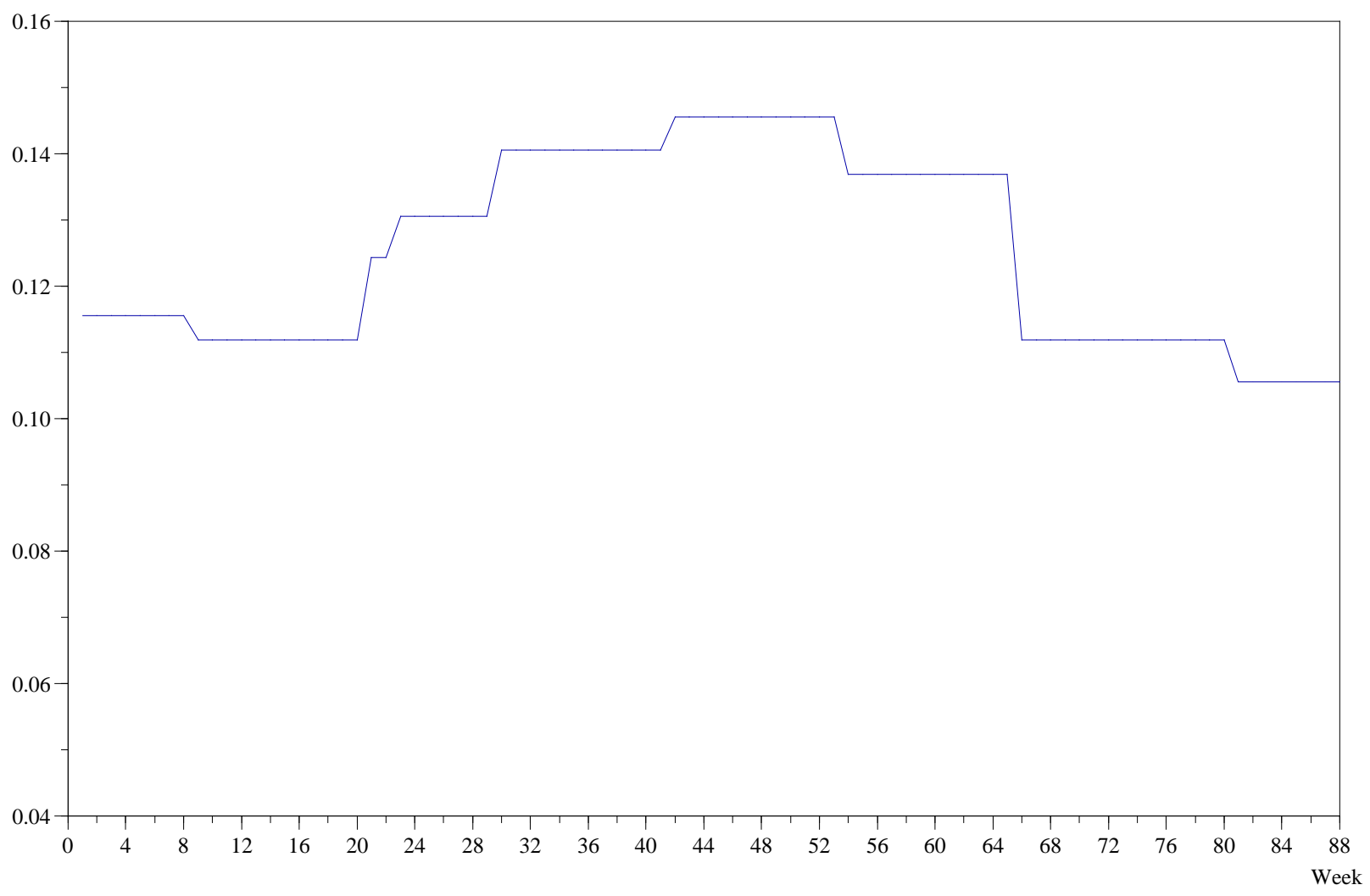


Figure 2.1. Cumulative Impulse Response Functions: Refrigerated Tropicana
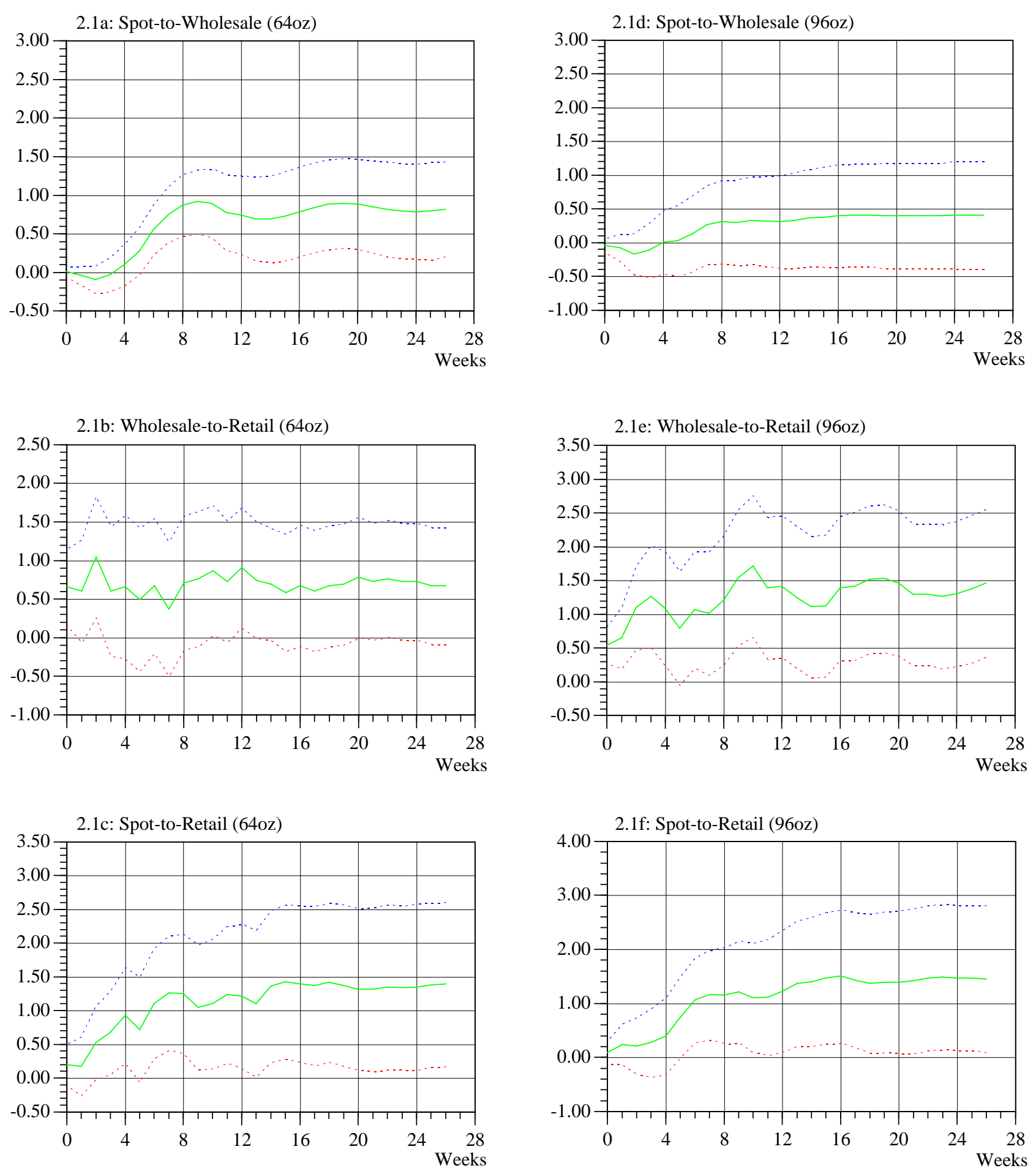
Figure 2.2. Cumulative Impulse Response Functions: Refrigerated Minute Maid

2.2a: Spot-to-Wholesale (64oz)

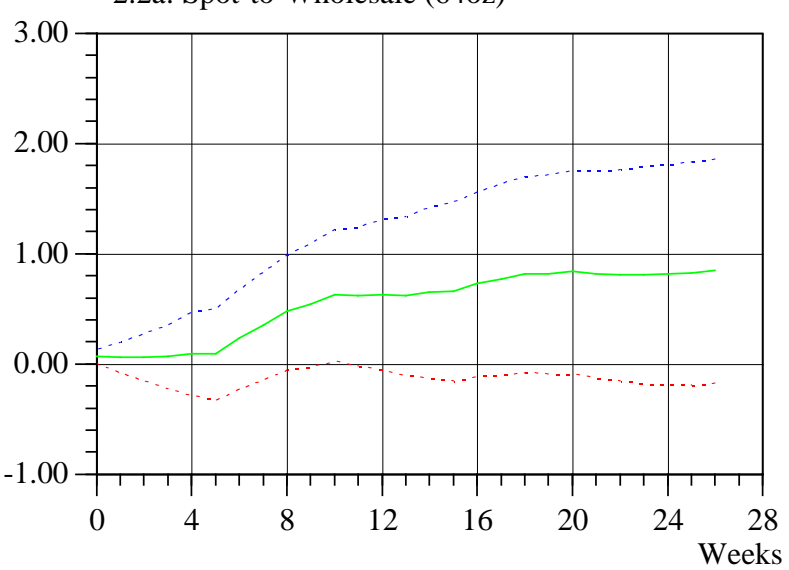

2.2b: Wholesale-to-Retail (64oz)

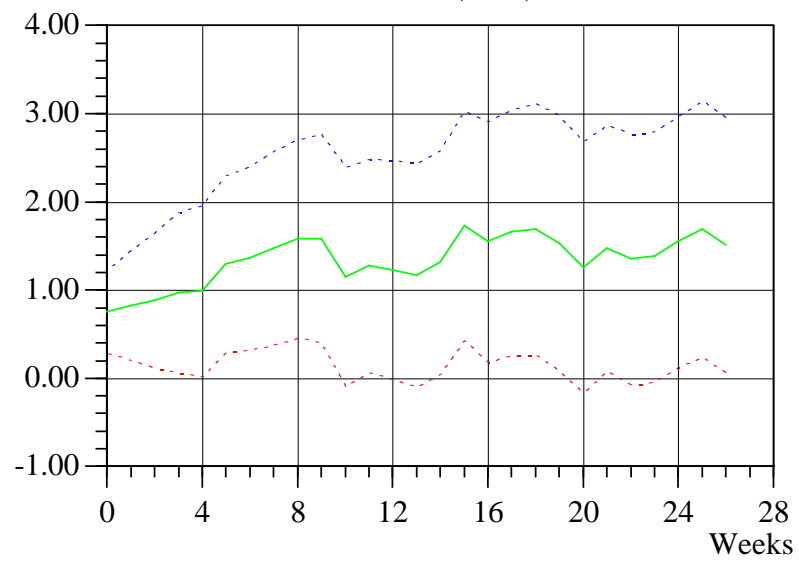

2.2c: Spot-to-Retail (64oz)

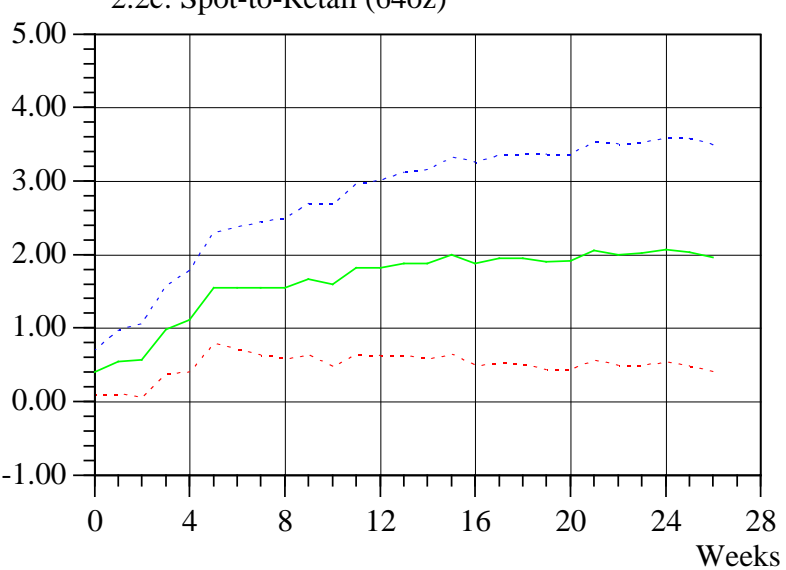

2.2d: Spot-to-Wholesale (96oz)

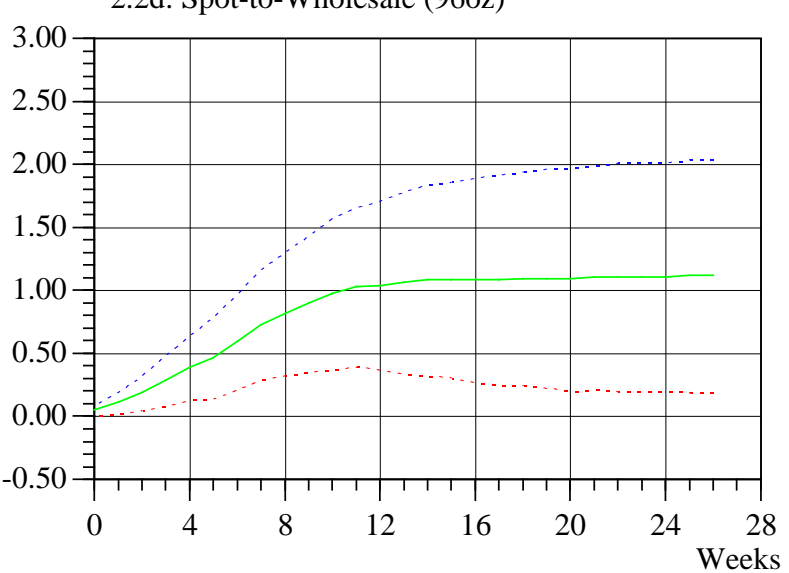

2.2e: Wholesale-to-Retail (96oz)
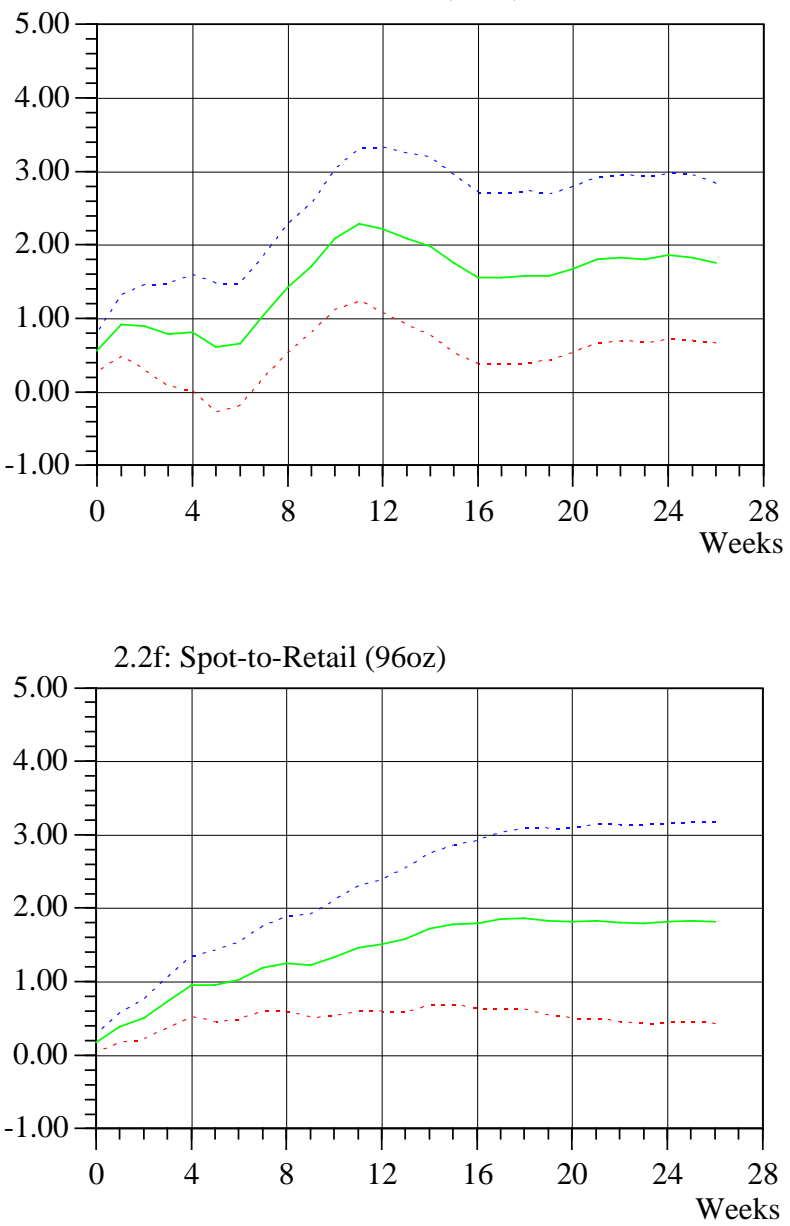
Figure 2.3. Cumulative Impulse Response Functions: Refrigerated Heritage House

2.3a: Spot-to-Wholesale (64oz)

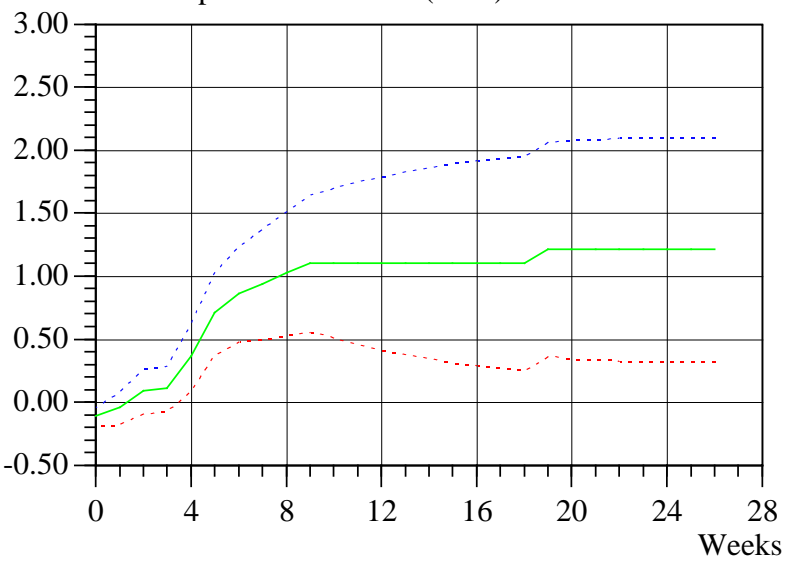

2.3b: Wholesale-to-Retail (64oz)

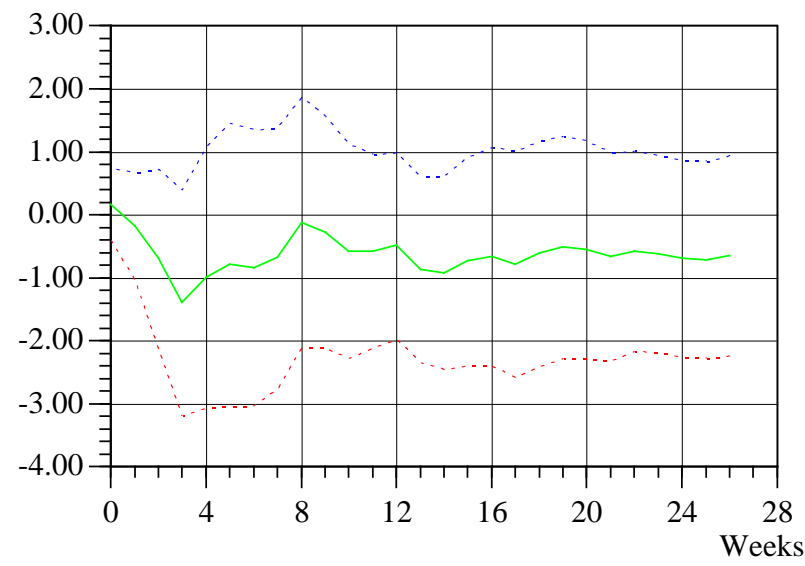

2.3c: Spot-to-Retail (64oz)

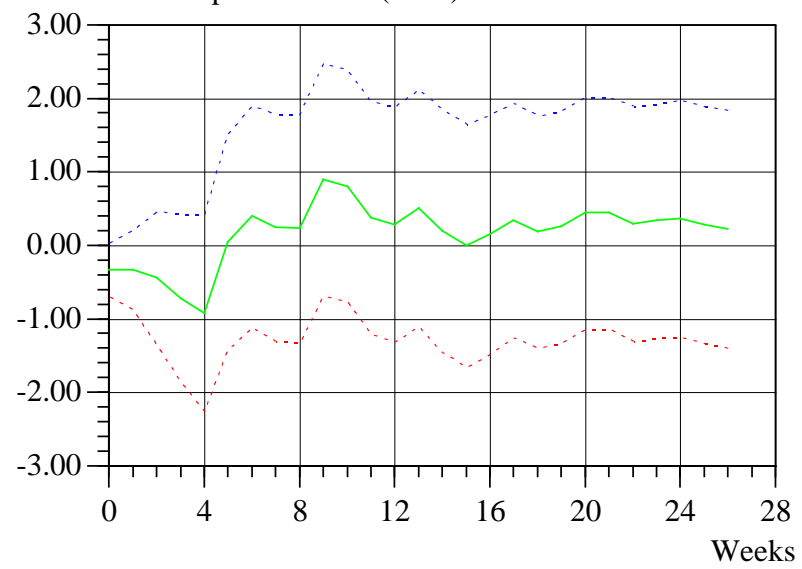

2.3d: Spot-to-Wholesale (128oz)

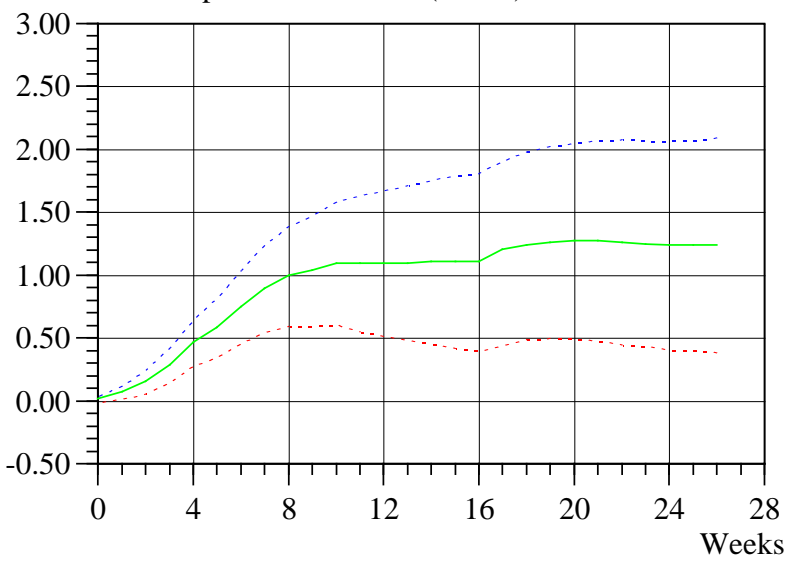

2.3e: Wholesale-to-Retail (128oz)

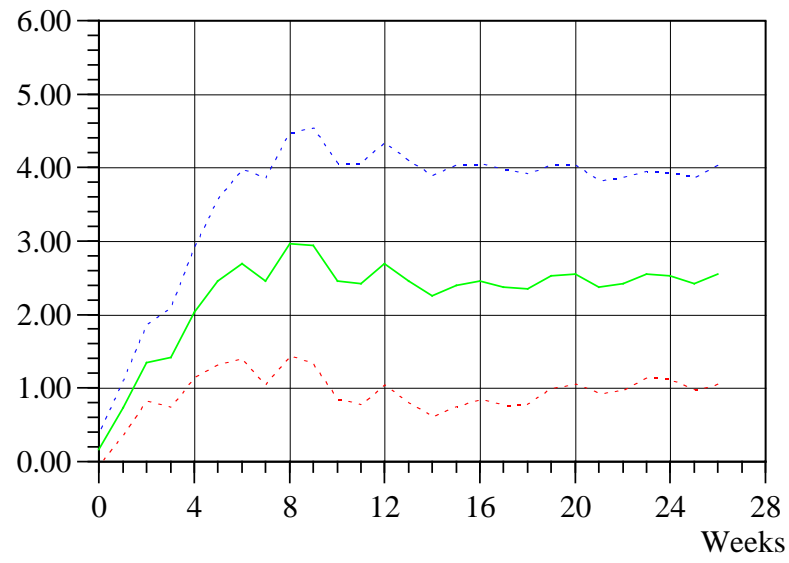

2.3f: Spot-to-Retail (128oz)

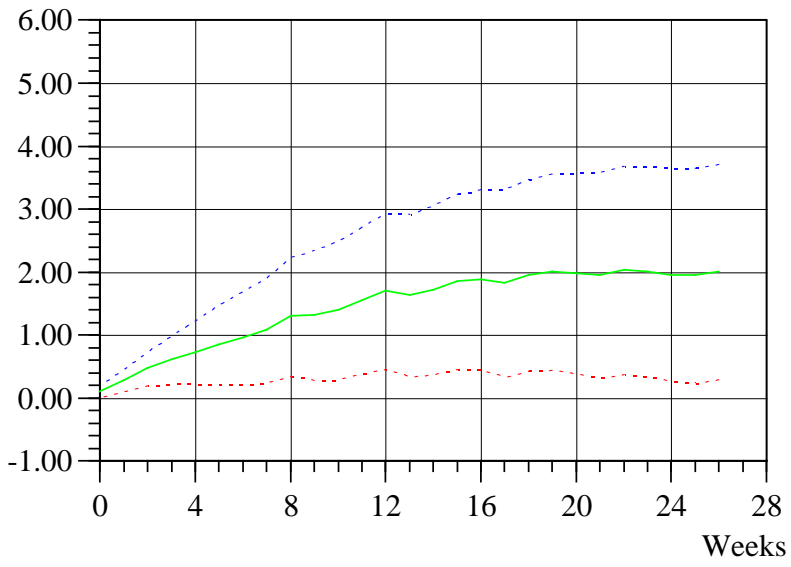


Figure 2.4. Cumulative Impulse Response Functions: Frozen Tropicana

2.4a: Spot-to-Wholesale (12oz)

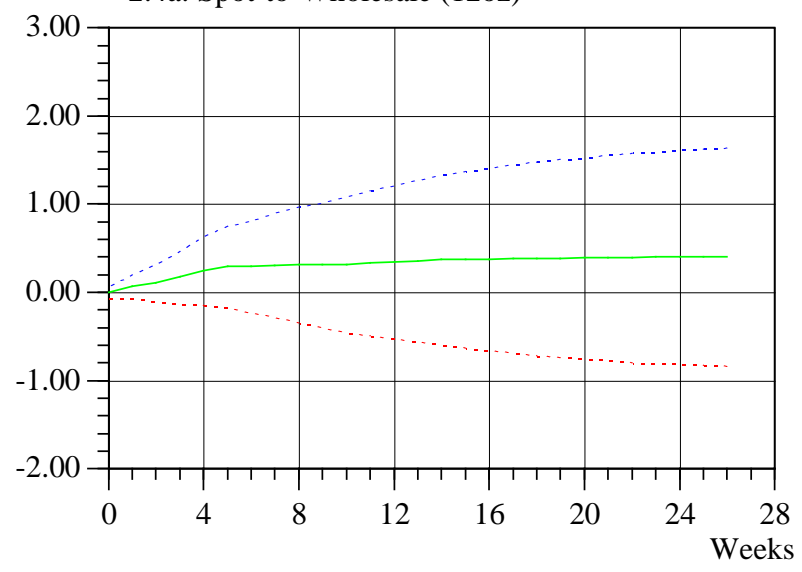

2.4b: Wholesale-to-Retail (12oz)

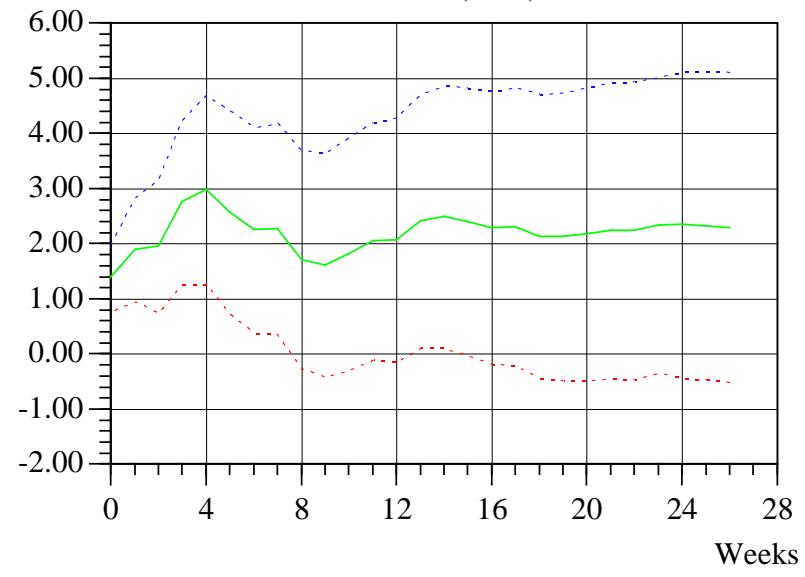

2.4c: Spot-to-Retail (12oz)

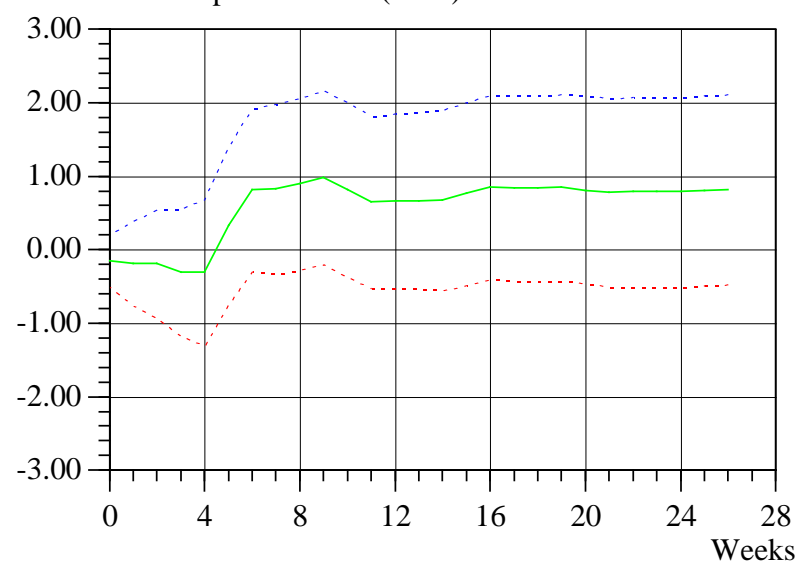

2.4d: Spot-to-Wholesale (16oz)

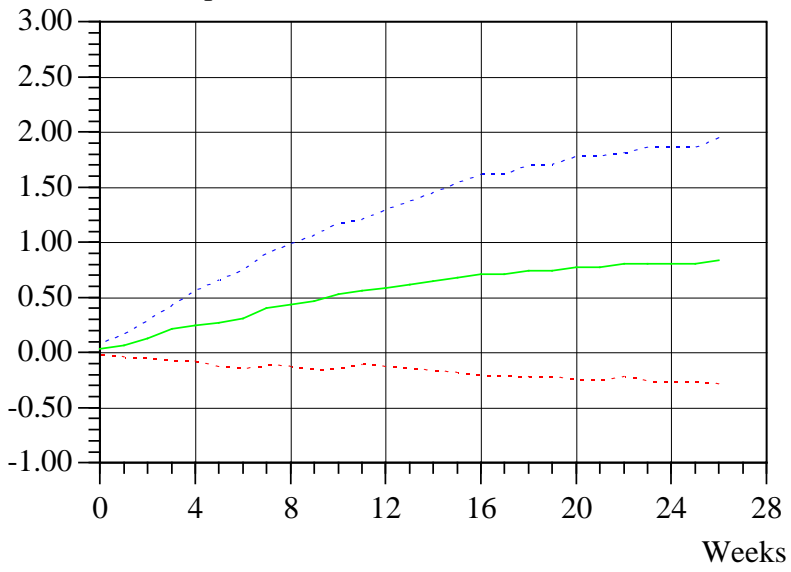

2.4e: Wholesale-to-Retail (16oz)

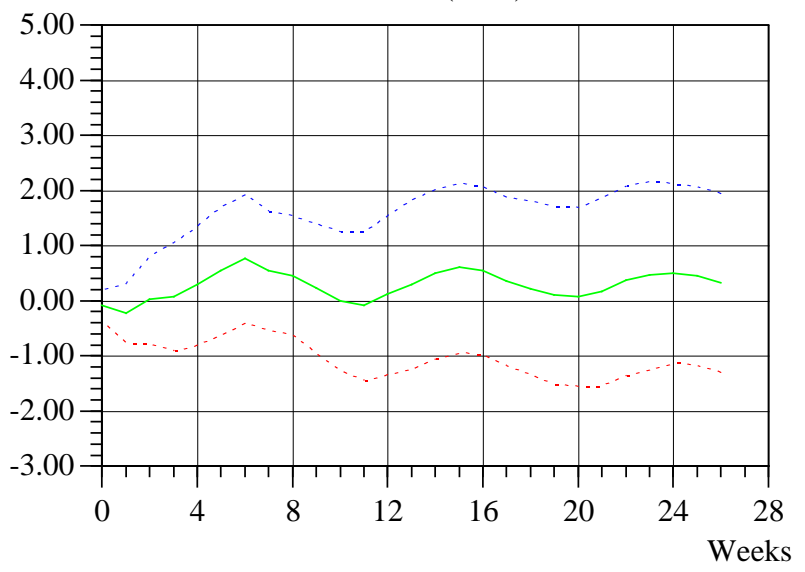

2.4f: Spot-to-Retail (16oz)

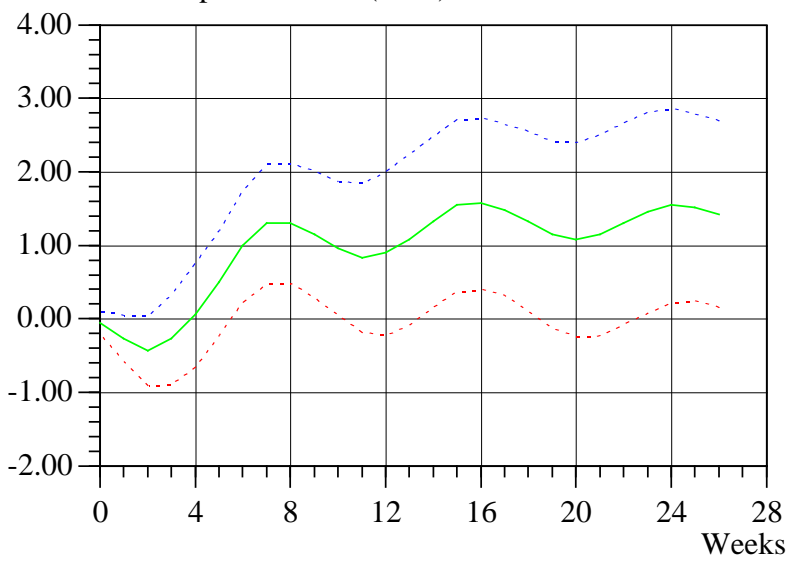


Figure 2.5. Cumulative Impulse Response Functions: Frozen Minute Maid
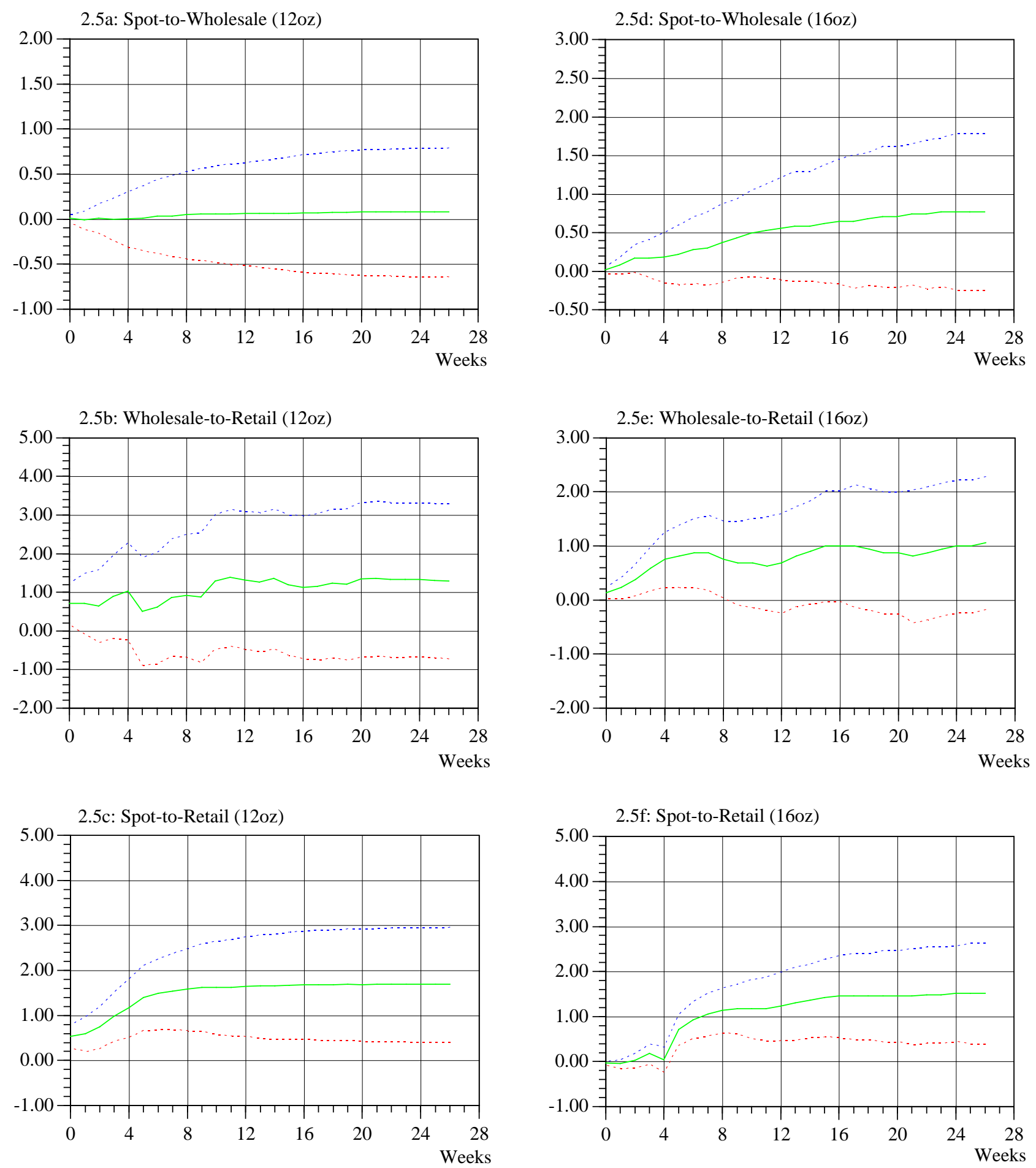
Figure 2.6. Cumulative Impulse Response Functions: Frozen Heritage House
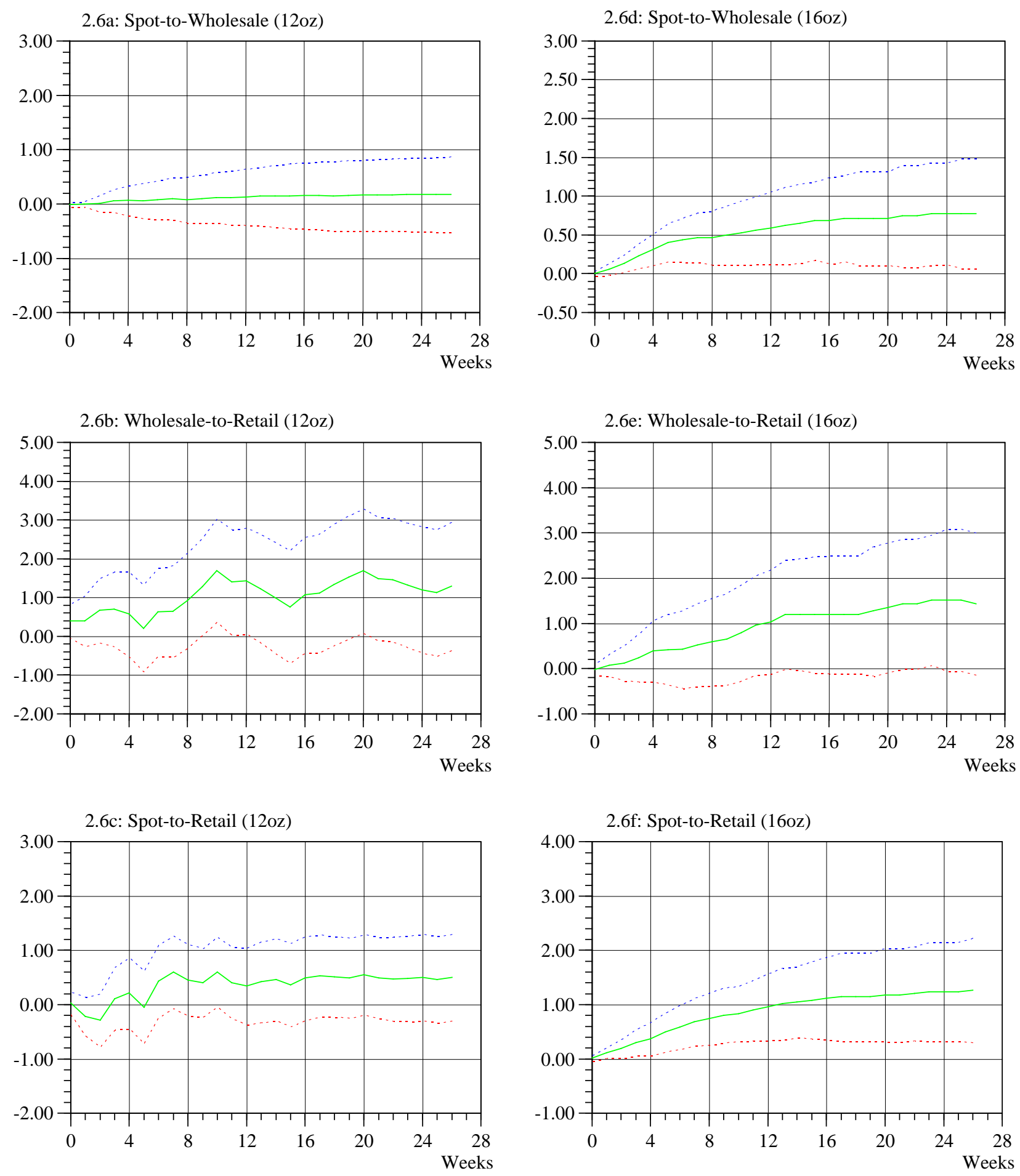
Figure 2.7. Variance Decomposition: Refrigerated Tropicana
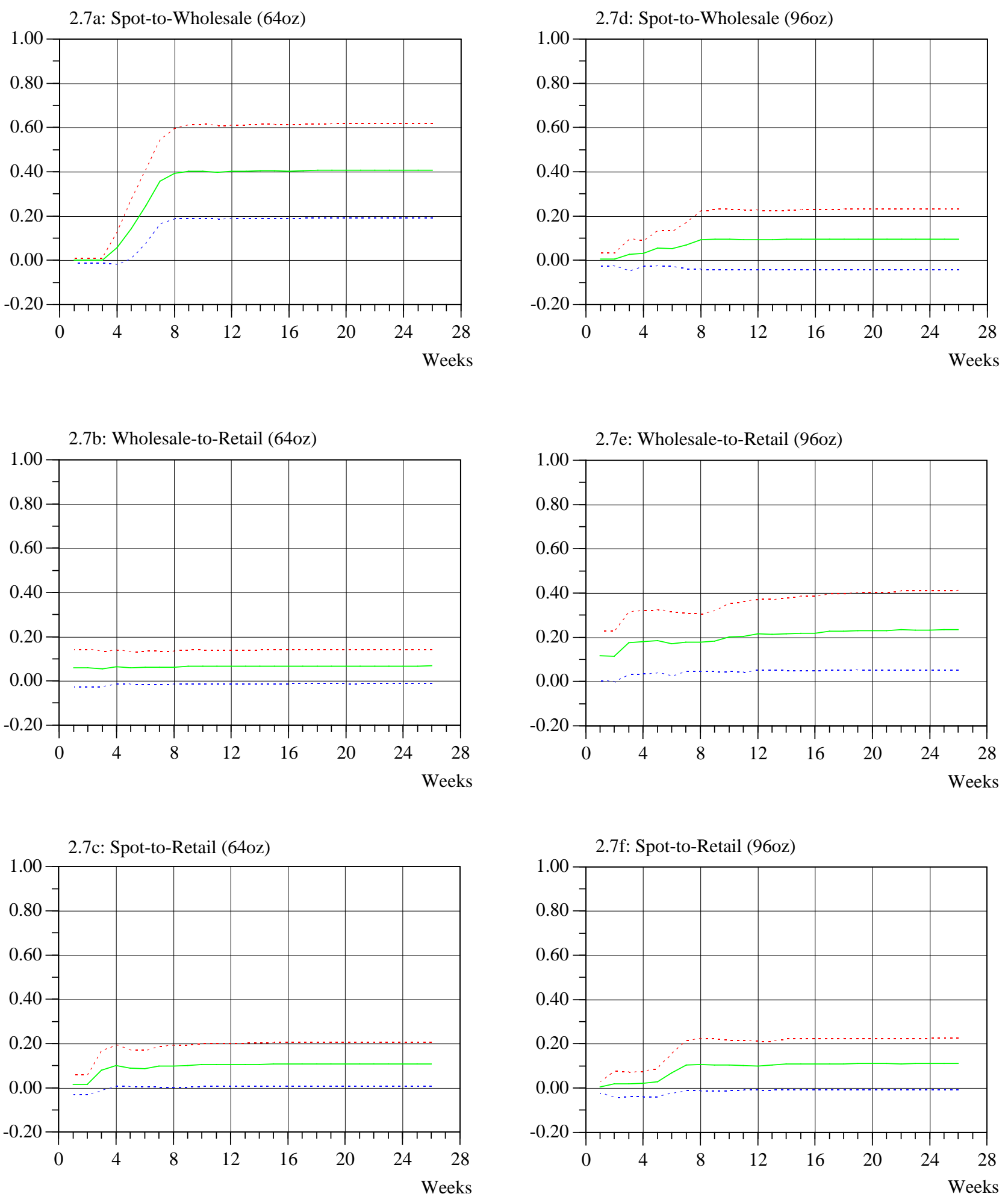
Figure 2.8. Variance Decomposition: Refrigerated Minute Maid
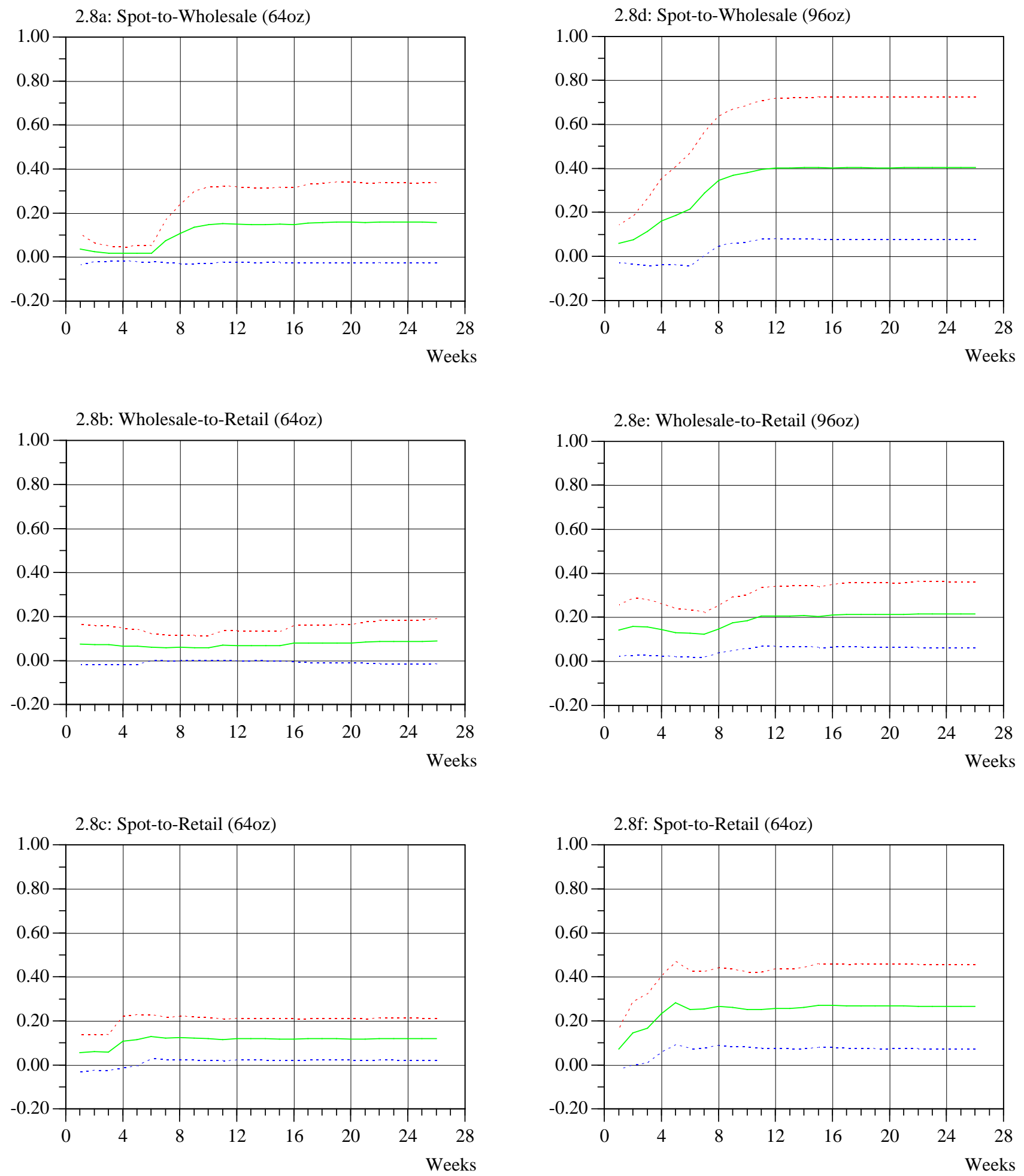
Figure 2.9. Variance Decomposition: Refrigerated Heritage House
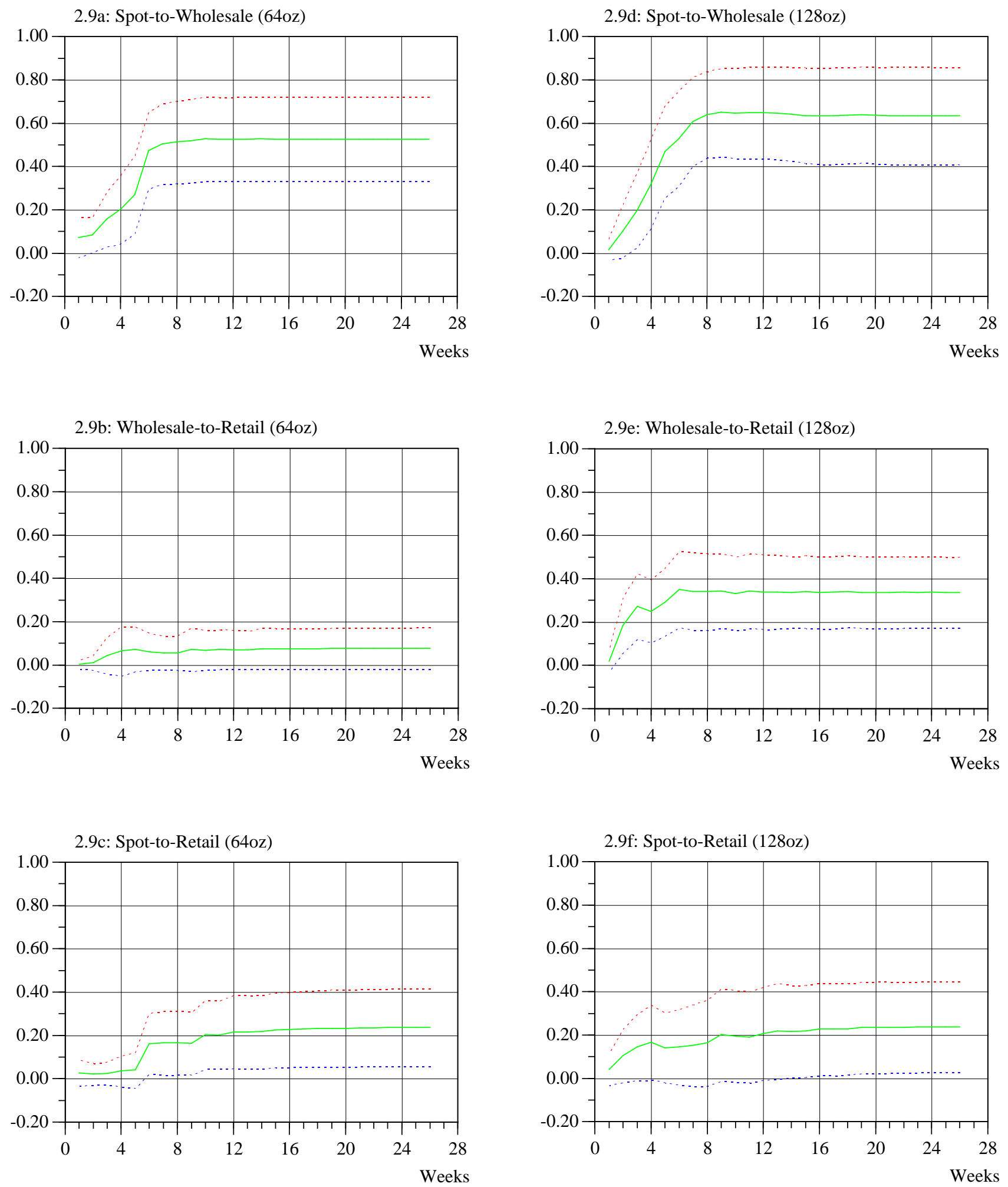
Figure 2.10. Variance Decomposition: Frozen Tropicana

2.10a: Spot-to-Wholesale (12oz)

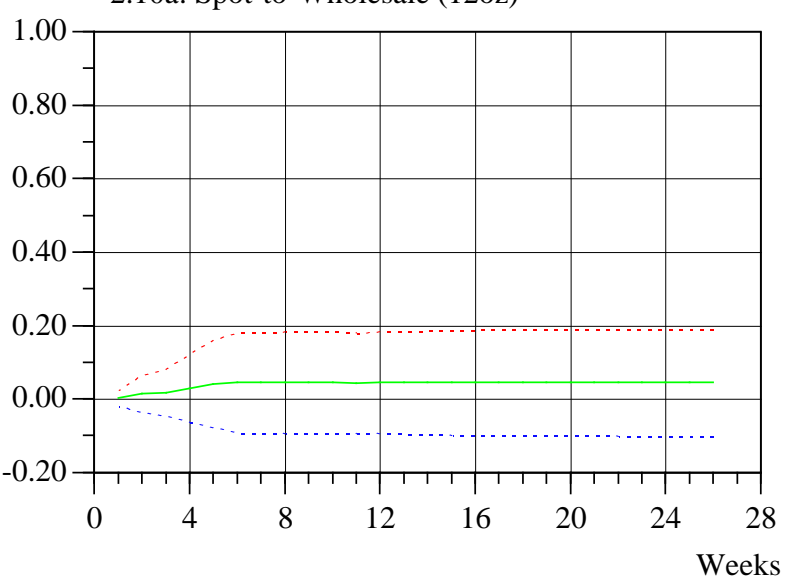

2.10b: Wholesale-to-Retail (12oz)

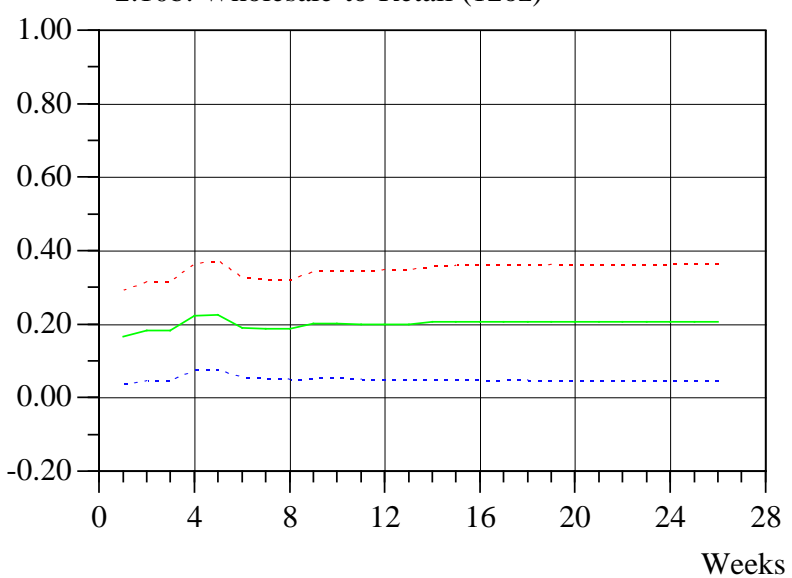

2.10c: Spot-to-Retail (12oz)

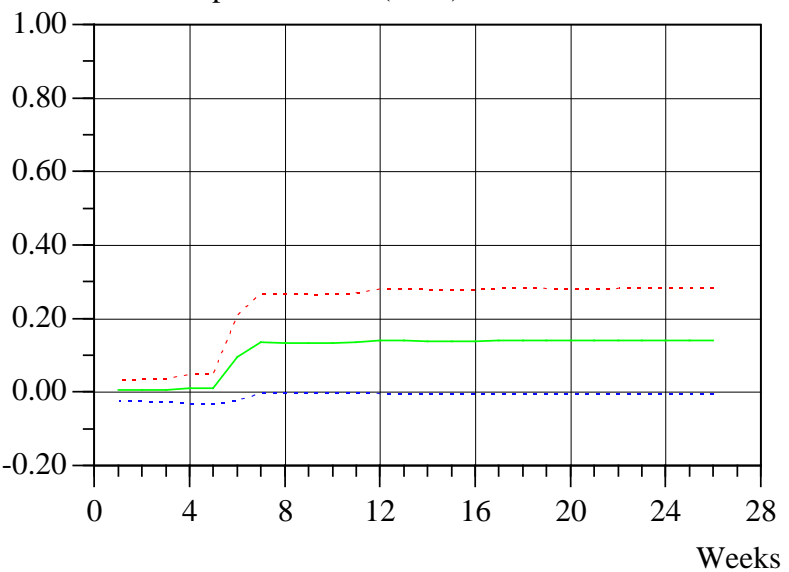

2.10d: Spot-to-Wholesale (16oz)

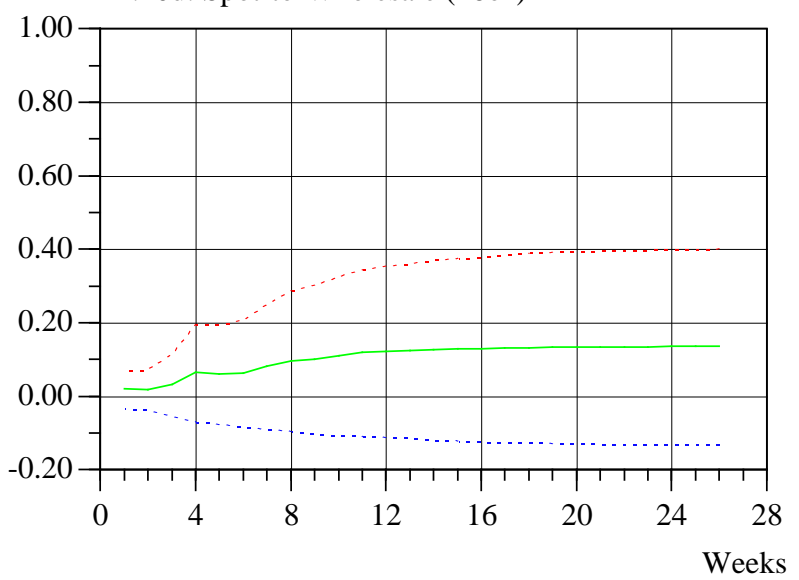

2.10e: Wholesale-to-Retail (16oz)

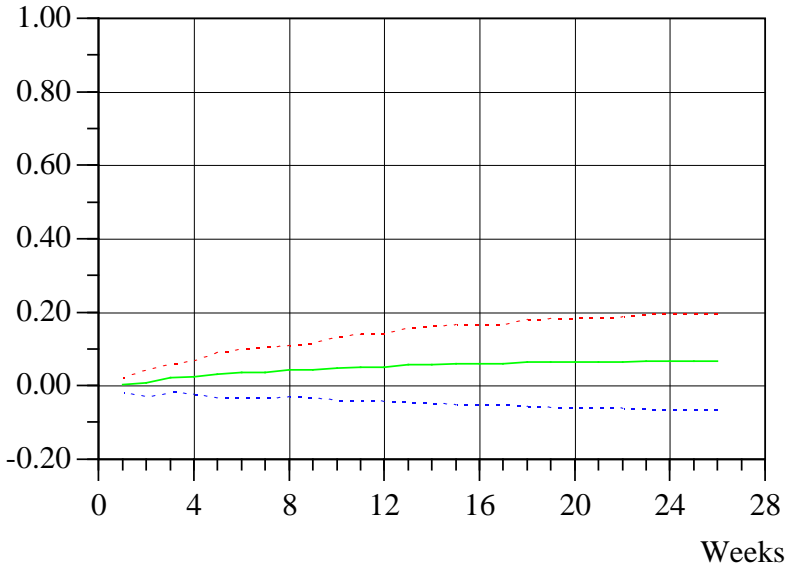

2.10f: Spot-to-Retail (16oz)

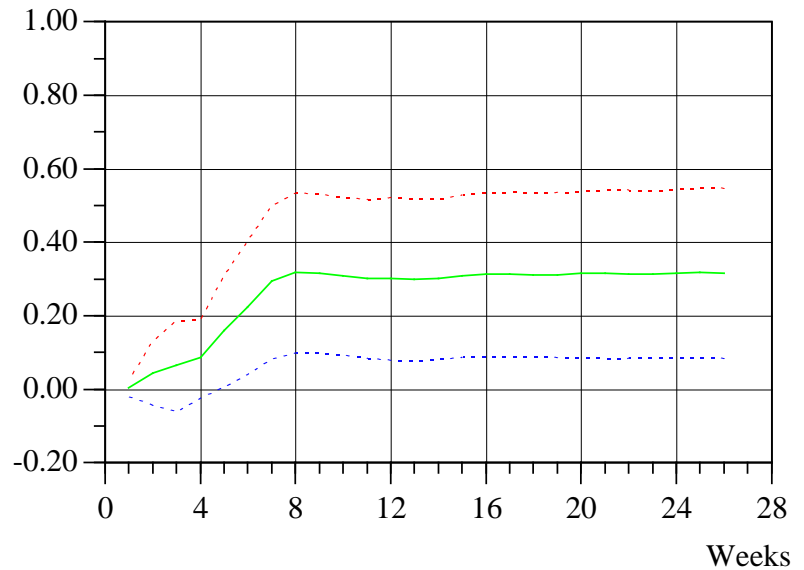


Figure 2.11. Variance Decomposition: Frozen Minute Maid

2.11a: Spot-to-Wholesale (12oz)

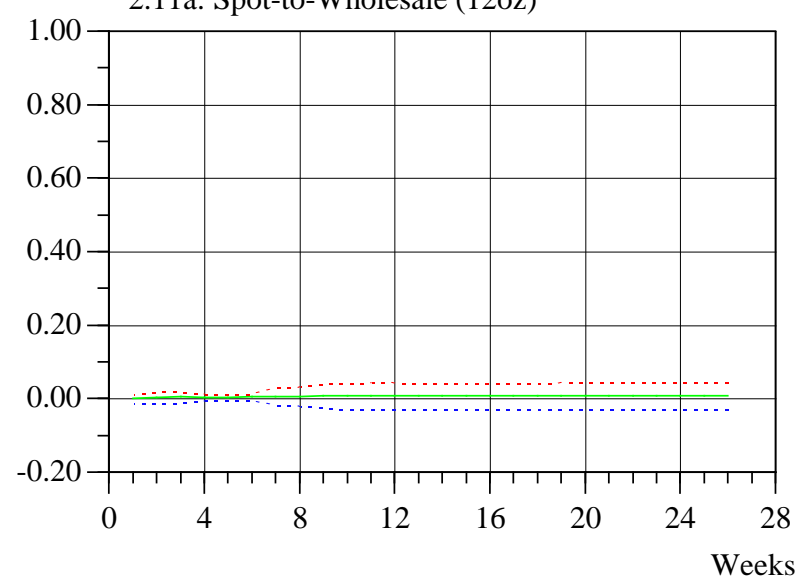

2.11b: Wholesale-to-Retail (12oz)

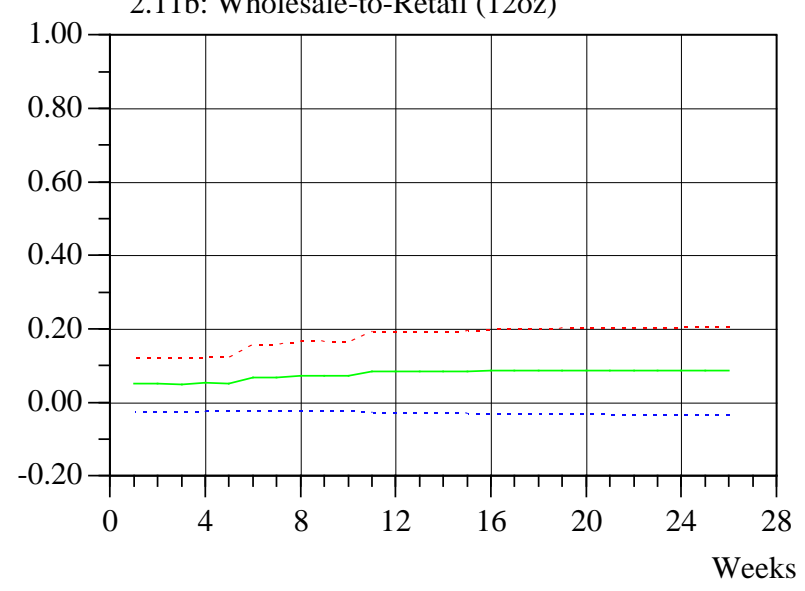

2.11c: Spot-to-Retail (12oz)

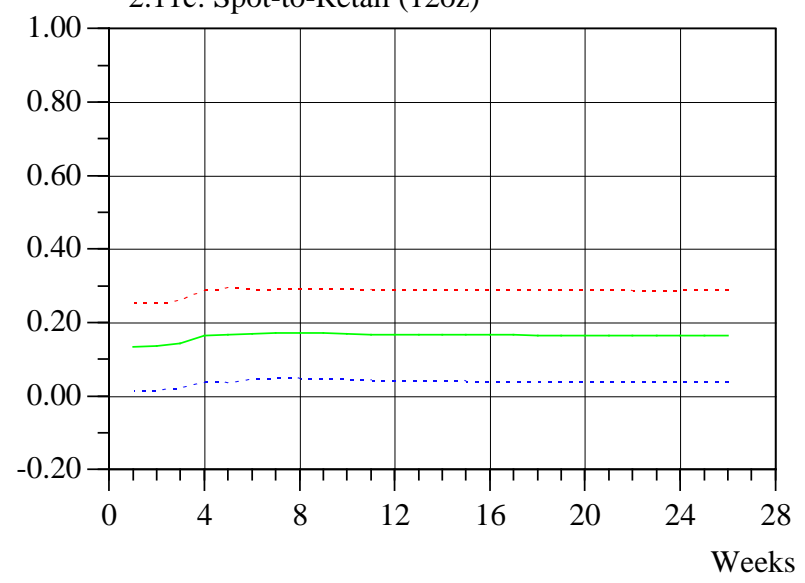

2.11d: Spot-to-Wholesale (16oz)

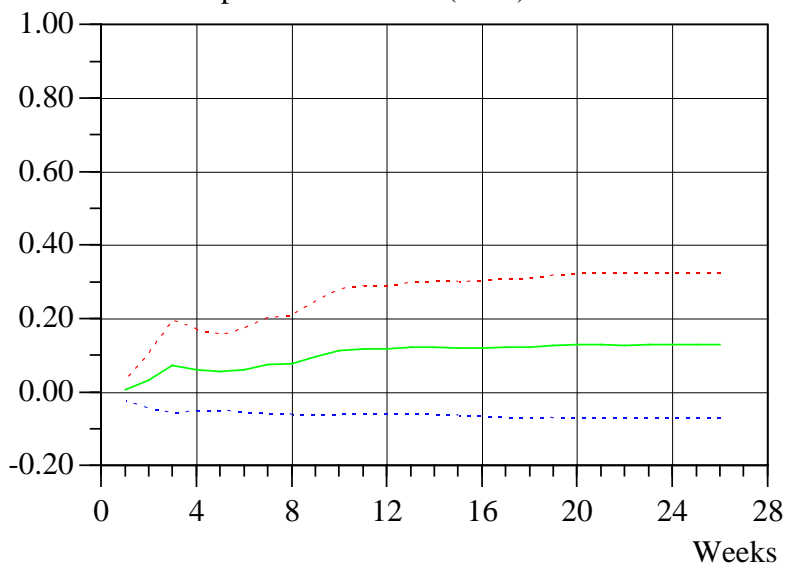

2.11e: Wholesale-to-Retail (16oz)

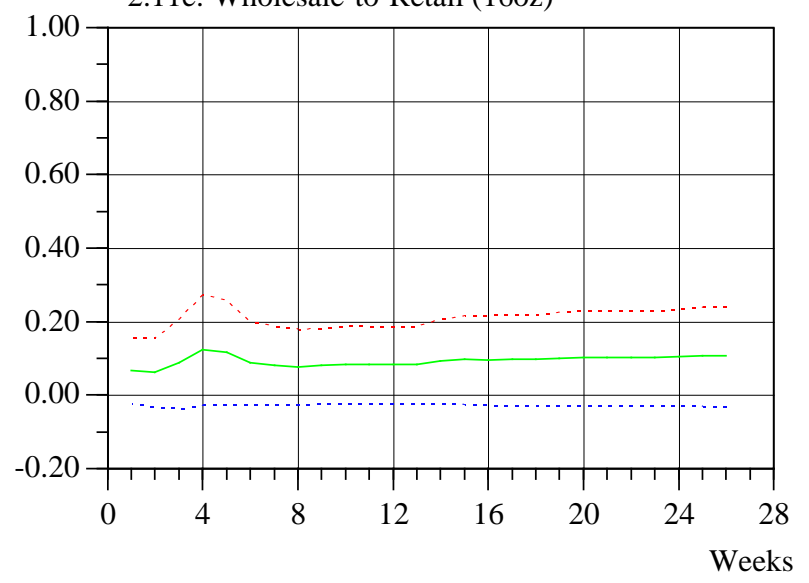

2.11f: Spot-to-Retail (16oz)

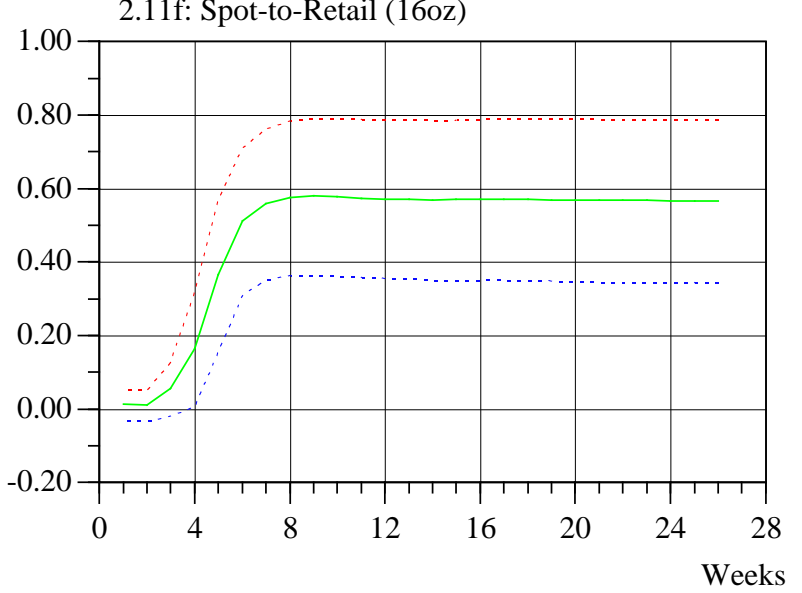


Figure 2.12. Variance Decomposition: Frozen Heritage House
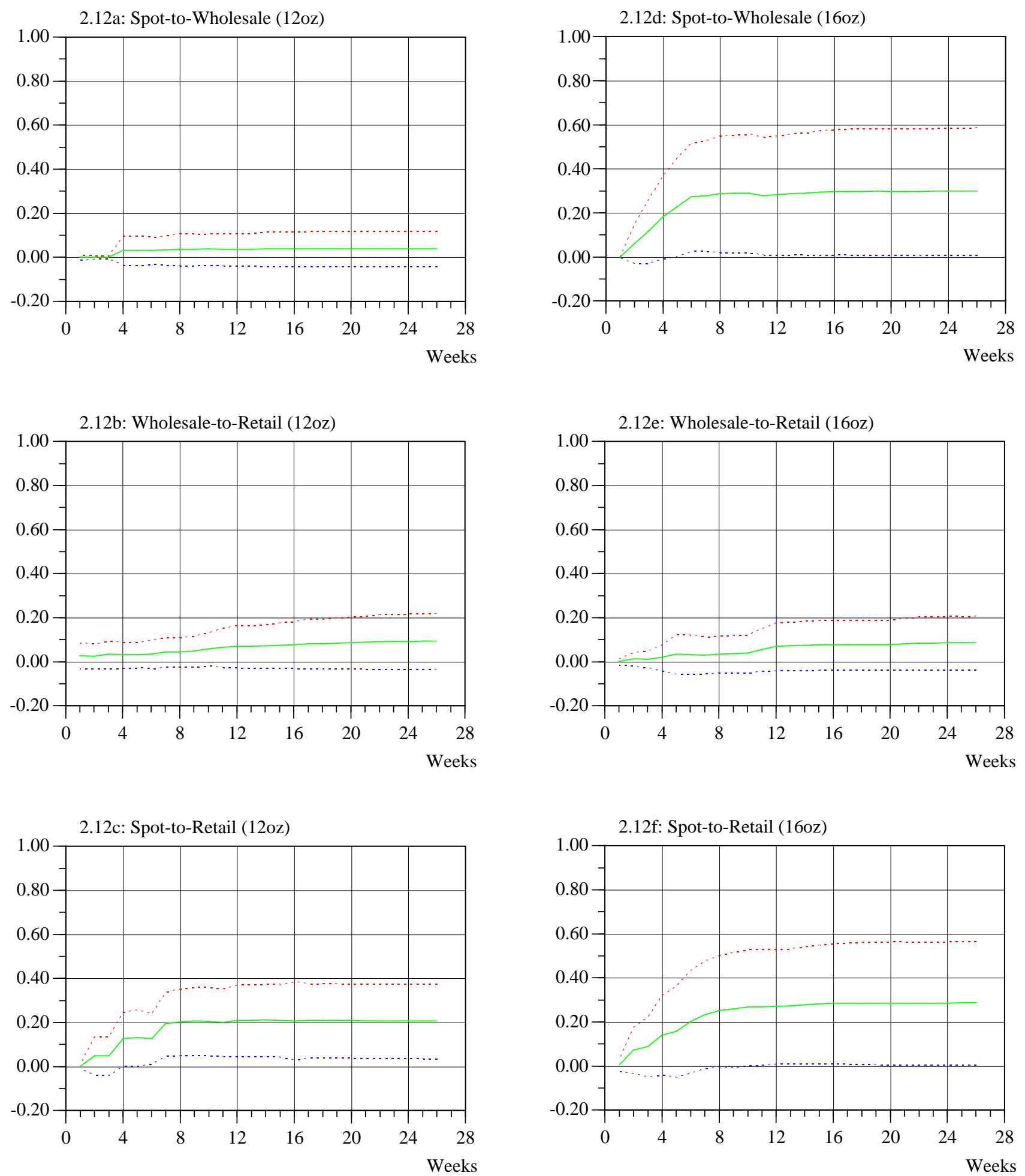


\section{Table 1}

Descriptive statistics of the spot price (dollars/oz or percents)

Mean Price (\$)

Standard Deviation

No. of Price Changes

Average No. of Weeks

between Price Changes

Average Absolute

Price Change (\$)

Average Absolute

Price Change (\%)

Maximum Absolute

Price Change (\$)

Maximum Absolute

Price Change (\%)

Minimum Absolute

Price Change (\$)

Minimum Absolute

Price Change (\%)
0.0692

0.0158

71

1.17

0.0026

4.00

0.01

17.36

0.0003

0.59

Notes:

1. Measurement units are provided parenthetically in column one $(\$$, or $\%)$.

2. Minimum Absolute $\Delta$ 's (last two rows) are computed as the lowest absolute changes found among non-zero changes. 
Table 2

Descriptive statistics of the wholesale prices of refrigerated orange juice (dollars/oz or percents)

\begin{tabular}{lcccccc}
$\begin{array}{l}\text { Brand } \\
\text { Size }\end{array}$ & $\begin{array}{c}\text { Heritage House } \\
64 \mathrm{oz}\end{array}$ & $\begin{array}{c}\text { Minute Maid } \\
64 \mathrm{oz}\end{array}$ & $\begin{array}{c}\text { Tropicana } \\
64 \mathrm{oz}\end{array}$ & $\begin{array}{c}\text { Heritage House } \\
128 \mathrm{oz}\end{array}$ & $\begin{array}{c}\text { Minute Maid } \\
96 \mathrm{oz}\end{array}$ & $\begin{array}{c}\text { Tropicana } \\
96 \mathrm{oz}\end{array}$ \\
\hline Mean Price (\$) & 0.0120 & 0.0273 & 0.1026 & 0.0217 & 0.0319 & 0.0373 \\
& & & & & & \\
Standard Deviation & 0.0035 & 0.0030 & 0.0026 & 0.0030 & 0.0034 & 0.0041 \\
& & & & & & \\
No. of Price Changes & 55 & 40 & 49 & 47 & 21 & 47
\end{tabular}

Average No. of Weeks

$\begin{array}{lllllll}\text { between Changes } & 1.51 & 2.08 & 1.69 & 1.76 & 3.95 & 1.76\end{array}$

Average Absolute

Price Change (\$)

0.0016

0.0013

0.0014

0.0007

0.0013

0.0022

Average Absolute

Price Change (\%)

8.56

4.96

5.37

3.62

4.11

6.31

Maximum Absolute

Price Change (\$)

0.0090

0.0075

0.0061

0.0030

0.0036

0.0104

Maximum Absolute

Price Change (\%)

60.13

27.05

24.05

13.96

11.71

29.59

Minimum Absolute

Price Change (\$)

0.0001

0.0002

0.0001

0.0001

0.0002

0.0002

Minimum Absolute

Price Change (\%)

0.63

0.52

0.59

0.50

0.53

0.64

Notes:

1. Measurement units are provided parenthetically in column one (unit free, $\$$, or \%).

2. Minimum Absolute $\Delta$ 's (last two rows) are computed as the lowest absolute changes found among non-zero changes. 
Table 3

Descriptive statistics of the wholesale prices of frozen concentrated orange juice (dollars/oz or percents)

Brand Heritage House Minute Maid Tropicana Heritage House Minute Maid Tropicana \begin{tabular}{lllllll} 
Size & $12 \mathrm{oz}$ & $12 \mathrm{oz}$ & $12 \mathrm{oz}$ & $16 \mathrm{oz}$ & $16 \mathrm{oz}$ & $16 \mathrm{oz}$ \\
\hline
\end{tabular}

\begin{tabular}{lllllll}
\hline Mean Price (\$) & 0.0784 & 0.1021 & 0.0854 & 0.0724 & 0.1038 & 0.0865
\end{tabular}

$\begin{array}{lllllll}\text { Standard Deviation } & 0.0102 & 0.0111 & 0.0131 & 0.0107 & 0.0119 & 0.0128\end{array}$

$\begin{array}{lllllll}\text { No. of Price Changes } & 35 & 31 & 19 & 13 & 24 & 7\end{array}$

Average No. of Weeks

$\begin{array}{lllllll}\text { between Changes } & 2.37 & 2.67 & 4.37 & 6.38 & 3.46 & 11.85\end{array}$

Average Absolute

Price Change (\$)

0.0038

0.0065

0.0055

0.0054

0.0011

Average Absolute

Price Change $(\%)$

$6.79 \quad 3.77$

8.13

7.34

5.41

12.72

Maximum Absolute

Price Change (\$)

0.0167

0.0162

0.0203

0.0124

0.0222

0.0241

Maximum Absolute

Price Change (\%)

25.22

18.09

30.61

14.32

24.99

28.45

Minimum Absolute

Price Change (\$)

0.0010

0.0008

0.0008

0.0005

0.0009

0.0005

Minimum Absolute

Price Change (\%)

1.35

0.72

0.82

0.72

0.87

0.68

Notes:

1. Measurement units are provided parenthetically in column one (unit free, \$, or \%).

2. Minimum Absolute $\Delta$ 's (last two rows) are computed as the lowest absolute changes found among non-zero changes. 
Table 4

Descriptive statistics of the original and smoothed retail prices of refrigerated orange juice (dollars/oz or percents)

\begin{tabular}{|c|c|c|c|c|c|c|}
\hline $\begin{array}{l}\text { Brand } \\
\text { Size }\end{array}$ & $\begin{array}{l}\text { Heritage House } \\
\qquad 64 \mathrm{oz}\end{array}$ & $\begin{array}{l}\text { Minute Maid } \\
64 \mathrm{oz}\end{array}$ & $\begin{array}{c}\text { Tropicana } \\
64 \mathrm{oz}\end{array}$ & $\begin{array}{l}\text { Heritage House } \\
128 \mathrm{oz}\end{array}$ & $\begin{array}{l}\text { Minute Maid } \\
960 z\end{array}$ & $\begin{array}{c}\text { Tropicana } \\
960 z\end{array}$ \\
\hline Mean Price (\$) & 0.0322 & 0.0405 & 0.0383 & 0.0344 & 0.0474 & 0.0545 \\
\hline —of Smoothed Series & 0.0353 & 0.0435 & 0.0424 & 0.0352 & 0.0477 & 0.0560 \\
\hline StandardDeviation & 0.0085 & 0.0079 & 0.0068 & 0.0046 & 0.0049 & 0.0068 \\
\hline — of Smoothed Series & 0.0076 & 0.0067 & 0.0044 & 0.0040 & 0.0042 & 0.0047 \\
\hline No. of Price Changes & 38 & 43 & 51 & 27 & 30 & 22 \\
\hline —of Smoothed Series & 4 & 11 & 10 & 9 & 12 & 7 \\
\hline Average\#Weeks b/n $\Delta^{\prime}$ 's & 2.18 & 1.93 & 1.63 & 3.07 & 2.77 & 3.77 \\
\hline —of Smoothed Series & 20.75 & 6.90 & 7.70 & 8.66 & 6.25 & 11.42 \\
\hline Average Absolute $\Delta$ (\$) & 0.0130 & 0.0119 & 0.0111 & 0.0046 & 0.0044 & 0.0106 \\
\hline —of Smoothed Series & 0.0089 & 0.0086 & 0.0080 & 0.0047 & 0.0043 & 0.0073 \\
\hline Average Absolute $\Delta(\%)$ & 45.23 & 30.99 & 30.64 & 14.57 & 9.18 & 21.61 \\
\hline — of Smoothed Series & 34.24 & 25.58 & 21.33 & 16.23 & 9.57 & 14.86 \\
\hline Maximum Absolute $\Delta(\$)$ & 0.0266 & 0.0184 & 0.0172 & 0.0117 & 0.0083 & 0.0188 \\
\hline —of Smoothed Series & 0.0125 & 0.0184 & 0.0143 & 0.0117 & 0.0083 & 0.0182 \\
\hline MaximumAbsolute $\Delta(\%)$ & 99.96 & 47.90 & 55.29 & 40.66 & 17.10 & 40.64 \\
\hline — of Smoothed Series & 55.46 & 71.94 & 44.44 & 50.16 & 15.71 & 42.89 \\
\hline Minimum Absolute $\Delta(\$)$ & 0.0016 & 0.0016 & 0.0027 & 0.0008 & 0.0016 & 0.0004 \\
\hline —of Smoothed Series & 0.0084 & 0.0015 & 0.0026 & 0.0007 & 0.0015 & 0.0004 \\
\hline MinimumAbsolute $\Delta(\%)$ & 5.43 & 3.94 & 6.96 & 2.02 & 3.14 & 0.69 \\
\hline —of Smoothed Series & 25.11 & 3.86 & 6.71 & 2.00 & 3.09 & 0.69 \\
\hline
\end{tabular}

Notes:

1. Measurement units are provided parenthetically in column one (unit free, \$, or \%).

2. Minimum Absolute $\Delta$ 's (last two rows) are computed as the lowest absolute changes found among non-zero changes. 
Table 5

Descriptive statistics of the original and smoothed retail prices of frozen concentrated orange juice (dollars/oz or percents)

Brand

Size

Heritage House Minute Maid Tropicana Heritage House Minute Maid Tropicana

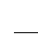

Mean Price $(\$)$

$12 \mathrm{oz}$

$12 \mathrm{oz}$

$12 \mathrm{oz}$

$16 \mathrm{oz}$

$16 \mathrm{oz}$

$16 \mathrm{oz}$

—of Smoothed Series

0.1199

0.1542

0.1403

0.1262

0.1635

0.1378

0.1288

0.1630

0.1537

0.1472

StandardDeviation

0.0208

0.0254

0.0282

0.0145

0.0159

0.0199

— of Smoothed Series

0.0123

0.0169

0.0201

0.0142

No. of Price Changes

—of Smoothed Series

39

36

38

8

12

28

7

6

7

Average\#Weeks b/n $\Delta$ 's

2.13

2.31

2.18

10.37

6.92

2.96

— of Smoothed Series

8.66

11.42

13.50

11.42

Average Absolute $\Delta(\$)$

0.0331

0.0378

0.0453

0.0097

0.0090

0.0208

0.0111

0.0150

0.0234

0.0258

Average Absolute $\Delta(\%)$

30.72

27.26

35.89

7.72

5.65

15.43

8.69

9.25

15.78

18.30

MaximumAbsolute $\Delta(\$)$

0.0583

0.0675

0.0858

0.0250

0.0225

0.0544

0.0216

0.0208

0.0558

0.0387

MaximumAbsolute $\Delta(\%)$

53.47

59.78

69.95

20.17

14.03

41.73

13.73

43.22

30.76

MinimumAbsolute $\Delta(\$)$

0.0833

0.0167

0.0217

0.0038

0.0013

0.0063

0.0034

0.0100

0.0125

0.0137

MinimumAbsolute $\Delta(\%)$

5.75

9.58

18.36

3.30

0.81

3.88

2.58

5.79

6.75

Notes:

1. Measurement units are provided parenthetically in column one (unit free, \$, or \%).

2. Minimum Absolute $\Delta$ 's (last two rows) are computed as the lowest absolute changes found among non-zero changes.

3. Heritage House and Minute Maid, 16oz, frozen concentrated orange juices were not on sale during the sample period. 
Table 6

Augmented Dickey-Fuller Unit Root Test $t$-Statistics

\begin{tabular}{|c|c|c|c|c|c|}
\hline Series & Type & Size & Brand & $\begin{array}{l}\text { ADF } t \text {-statistic: } \\
\text { Levels }\end{array}$ & $\begin{array}{l}\text { ADF } t \text {-statistic: } \\
\text { First Differences }\end{array}$ \\
\hline \multirow[t]{4}{*}{ Retail } & Refrigerated & $64 \mathrm{oz}$ & $\begin{array}{l}\text { Tropicana } \\
\text { Minute Maid } \\
\text { In-House }\end{array}$ & $\begin{array}{l}-2.64 \\
-2.39 \\
-3.39 c\end{array}$ & $\begin{array}{l}-3.79^{b} \\
-5.11^{a} \\
-6.82^{a}\end{array}$ \\
\hline & & $960 z$ & $\begin{array}{l}\text { Tropicana } \\
\text { Minute Maid } \\
\text { In-House (128oz) }\end{array}$ & $\begin{array}{l}-1.31 \\
-1.41 \\
-2.61\end{array}$ & $\begin{array}{l}-6.59^{a} \\
-5.48^{a} \\
-4.92^{a}\end{array}$ \\
\hline & Frozen & $12 \mathrm{oz}$ & $\begin{array}{l}\text { Tropicana } \\
\text { Minute Maid } \\
\text { In-House }\end{array}$ & $\begin{array}{l}-2.16 \\
-2.48 \\
-2.61\end{array}$ & $\begin{array}{l}-4.71^{a} \\
-4.02^{b} \\
-6.28^{a}\end{array}$ \\
\hline & & $16 \mathrm{oz}$ & $\begin{array}{l}\text { Tropicana } \\
\text { Minute Maid } \\
\text { In-House }\end{array}$ & $\begin{array}{l}-1.38 \\
-1.01 \\
-1.10\end{array}$ & $\begin{array}{l}-5.79^{a} \\
-4.32^{a} \\
-4.16^{a}\end{array}$ \\
\hline \multirow[t]{4}{*}{ Wholesale } & Refrigerated & $64 \mathrm{oz}$ & $\begin{array}{l}\text { Tropicana } \\
\text { Minute Maid } \\
\text { In-House }\end{array}$ & $\begin{array}{l}-1.77 \\
-1.13 \\
-2.26\end{array}$ & $\begin{array}{l}-5.17^{a} \\
-5.16^{a} \\
-4.21^{a}\end{array}$ \\
\hline & & $960 z$ & $\begin{array}{l}\text { Tropicana } \\
\text { Minute Maid } \\
\text { In-House (128oz) }\end{array}$ & $\begin{array}{l}-1.15 \\
-1.69 \\
-1.83\end{array}$ & $\begin{array}{l}-5.69^{a} \\
-3.99^{b} \\
-3.97^{b}\end{array}$ \\
\hline & Frozen & $12 \mathrm{oz}$ & $\begin{array}{l}\text { Tropicana } \\
\text { Minute Maid } \\
\text { In-House }\end{array}$ & $\begin{array}{l}-1.91 \\
-0.68 \\
-0.90\end{array}$ & $\begin{array}{l}-3.33^{c} \\
-4.82^{a} \\
-4.16^{a}\end{array}$ \\
\hline & & $16 \mathrm{oz}$ & $\begin{array}{l}\text { Tropicana } \\
\text { Minute Maid } \\
\text { In-House }\end{array}$ & $\begin{array}{l}-1.67 \\
-1.00 \\
-1.52\end{array}$ & $\begin{array}{l}-3.58^{b} \\
-4.63^{a} \\
-3.45^{c}\end{array}$ \\
\hline Spot & & & & -1.78 & $-3.57 b$ \\
\hline
\end{tabular}

Note: The superscripts $a, b$, and $c$ indicate a significance at $1 \%, 5 \%$, and $10 \%$, respectively. The critical values as tabulated in MacKinnon [1991] for $\alpha=1 \%, 5 \%$, and $10 \%$ are $-4.06,-3.46$, and -3.15 , respectively. The null hypothesis is $\mathrm{H}_{0}: x \sim I(1)$. The unit root test equation contains a constant, linear trend, and 6 lags. Heritage House refrigerated orange juice comparable to Tropicana and Minute Maid $960 z$ comes in $1280 z$ containers. 
Table 7

Cointegration Test Results

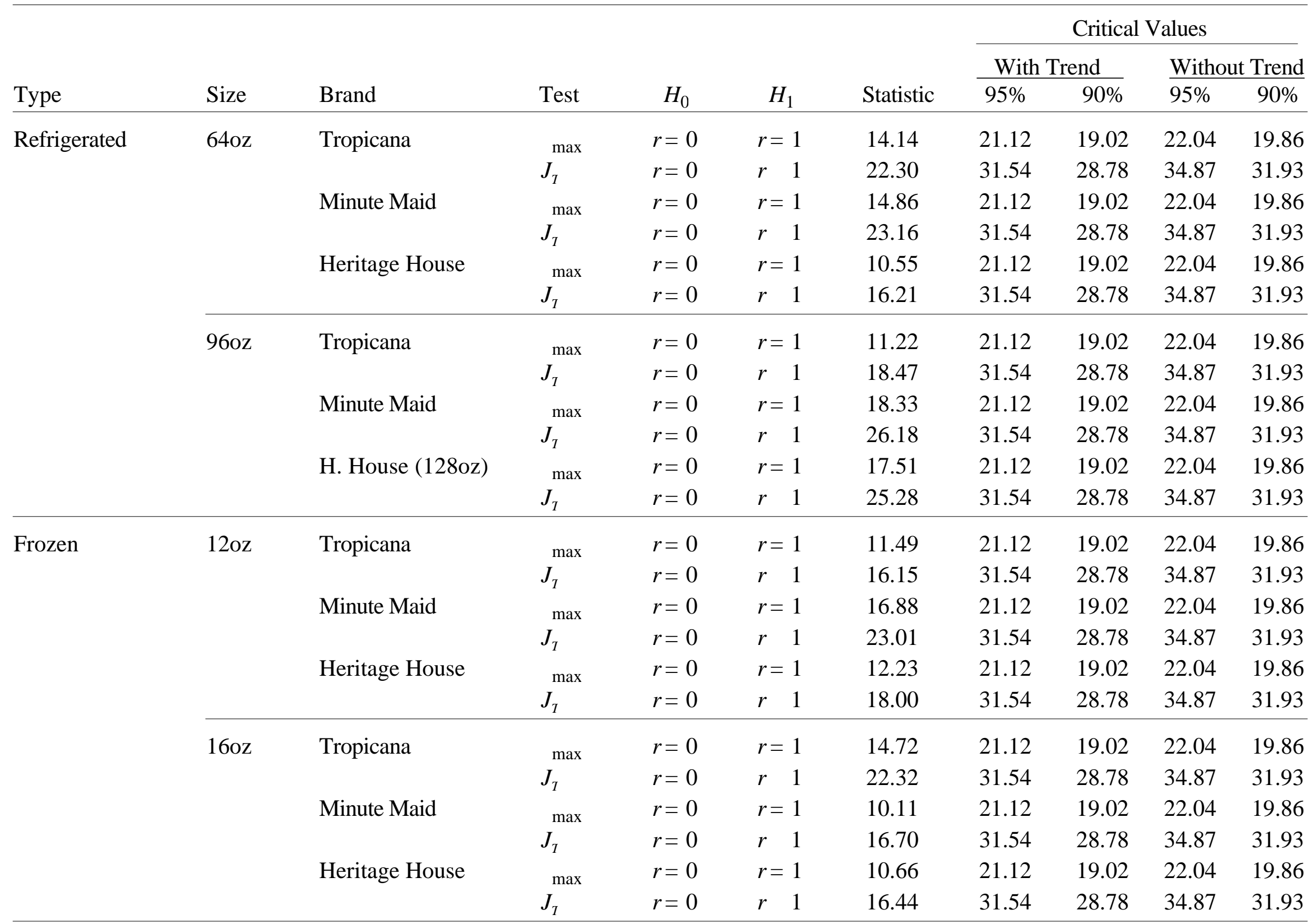


Table 8

VAR Residual Correlation Analysis

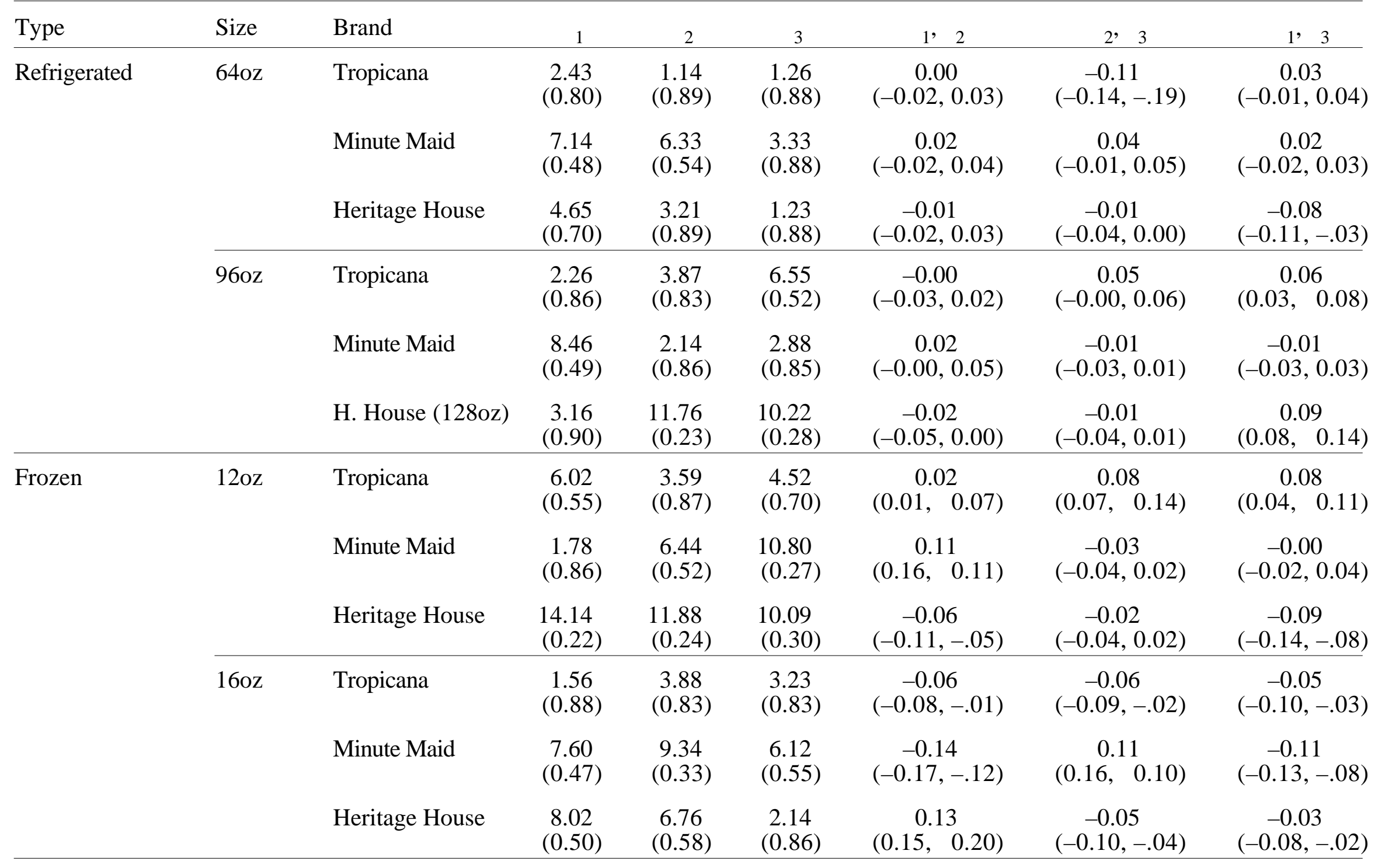

Note: First three columns report $\chi^{2}(m)$ statistic, $m=12$, along with corresponding $p$-values for each of the three VAR equations for testing residual autocorrelation. This is Godfrey's Lagrange multiplier version of the serial correlation test. The last three columns report the correlation between the residuals of the three equations of the VAR. Here the point estimates report the simple correlation estimate and the numbers underneath report 90 percent probability interval based on 5,000 draws from the distribution of the model coefficients (Leeper and Zha, 1999). See text for details. 
Table 9

Summary of the impulse response analysis: original data

\begin{tabular}{lcccc}
\hline Channel & Rigid & Tends toward rigid & Tends toward flexible & Flexible \\
\hline Spot-to-Wholesale & 6 & 0 & 0 & 6 \\
Wholesale-to-Retail & 3 & 0 & 0 & 9 \\
Spot-to-Retail & 1 & 1 & 3 & 7
\end{tabular}

Note: See the text for the definitions of the terms "rigid/flexible" and "tends towards rigid/flexible." 
Table 10

Summary of the impulse response analysis: moving averaged data

Channel Rigid Tends toward rigid Tends toward flexible Flexible

\begin{tabular}{lllll} 
Spot-to-Wholesale & 5 & 3 & 0 & 4 \\
Wholesale-to-Retail & 0 & 2 & 5 & 5 \\
Spot-to-Retail & 0 & 2 & 2 & 8 \\
\hline
\end{tabular}


Table 11

Summary of the impulse response analysis: smoothed data

Channel Rigid Tends toward rigid Tends toward flexible Flexible

\begin{tabular}{lllll} 
Spot-to-Wholesale & 5 & 1 & 0 & 6 \\
Wholesale-to-Retail & 0 & 1 & 2 & 9 \\
Spot-to-Retail & 1 & 1 & 0 & 10 \\
\hline
\end{tabular}

